\title{
Contemplative Education: A Systematic, Evidence-Based Review of the effect of Meditation Interventions in Schools
}

\author{
Lea Waters • Adam Barsky • Amanda Ridd • Kelly Allen
}

Published online: 4 March 2014

(C) The Author(s) 2014. This article is published with open access at Springerlink.com

\begin{abstract}
Schools need reliable evidence about the outcomes of meditation programs before they consider if and how such programmes can influence learning agendas, curriculum and timetables. This paper reviewed evidence from 15 peer-reviewed studies of school meditation programmes with respect to three student outcomes: well-being, social competence and academic achievement. In total, there were 76 results where effect sizes could be calculated. The overall number of participants in the effect size analyses was 1,797. Of the 76 effect sizes calculated, $61 \%$ were statistically significant. Sixty-seven per cent of the results had small effects on student outcomes, $24 \%$ of the results had medium effect strength and $9 \%$ showed a large effect of meditation upon student outcomes. Transcendental meditation programmes had a higher percentage of significant effects than mindfulness-based and other types of meditation programmes, but this may be to do with the settings and programme delivery rather than the technique itself. Programme elements such as duration, frequency of practice and type of instructor influenced student outcomes. A conceptual model is put forward based on two propositions: proposition 1 -meditation positively influences student success by increasing cognitive functioning; proposition 2-meditation positively influences student success by increasing emotional regulation. Suggestions are made to stimulate future research and to assist in the development of more efficacious applications for meditation in schools.
\end{abstract}

L. Waters $(\bowtie) \cdot K$. Allen

Melbourne Graduate School of Eduction, University of Melbourne, 100 Leicester Street, Parkville, VIC 3010, Australia

e-mail: 1.waters@unimelb.edu.au

A. Barsky

Department of Management and Marketing, Faculty of Business and Economics,

University of Melbourne, Melbourne, Australia

A. Ridd

School of Psychological Sciences, The Faculty of Medicine, Dentistry and Health Sciences,

University of Melbourne, Melbourne, Australia

e-mail: a.ridd@pgrad.unimelb.edu.au 
Keywords Meditation · Mindfulness · Academic achievement $\cdot$ Student well-being $\cdot$ Social competence $\cdot$ Cognitive function $\cdot$ Emotional regulation

\section{Meditation in Schools: Contemplative Education}

Contemplative education (CE) is defined as "a set of practices that may foster particular forms of awareness in students, forms conducive to the conscious motivation and regulation of learning, and also to freedom and transcendence in life more generally" (Roeser and Peck 2009, p. 119). CE aims to foster "personal growth and social transformation through the cultivation of conscious awareness and volition in an ethical-relational context" (p 120). Chano (2012) describes CE as "learning infused with the experience of awareness, insight and compassion for oneself and others honed through the practise of sitting meditation and other contemplative disciplines" (p. 106). Jennings (2008) suggests that the rigor of contemplative practices prepares the mind to process information in new ways and also assists students in learning about their inner selves. According to Grossenbacher and Parkin (2006):

Contemplative education challenges and supports students in ways that greatly expand upon traditional academic approaches. This innovative form of education equips students with perspectives and techniques useful for bringing forth their own genuine way of connecting their heart and mind (p. 1).

Although contemplative education has not typically formed part of school curriculum in the Western world, its use is on the rise, particularly through the practice of meditation in schools (Garrison Institute 2005; Jennings, 2008). Meditation refers to the deliberate act of regulating attention through the observation of thoughts, emotions and body states (Black et al. 2009; Zylowska et al. 2008). Among the popular meditation practices are acem, centering prayer, loving kindness meditation, mindfulness, mindfulness-based stress reduction programme, shamatha, transcendental meditation (TM), vipassana and zen (see Table 1). The underlying premise of all these techniques involves attending deliberately to internal and/or external phenomena with full concentration. Zylowska et al. (2008) outlined three steps involved in meditation practice: (1) directing focus to an "attentional anchor" (e.g. breath, an external object, a person whom we love, a deity), (2) dispassionately observing internal and external distractions and regularly disengaging from them and (3) focusing attention from distractions back to the attentional anchor. Meditation can be a secular practice and does not require any change in belief systems or religious affiliations (Kabat-Zinn, 1990).

Over the past 10 years, youth-meditation programmes have been developed in countries such as England (Mindfulness in Schools Project, DotB), the USA (Mindful Schools and MindUp), Canada (Mindful Education), Israel (The Mindfulness Language) and India (The Alice Project). It is worthy to note that, in 2012, the Collaborative for Academic, Social and Emotional Learning in the USA allocated \$7 million to the development of curriculum that promotes social-emotional learning (Wickelgren, 2012). As such, it is expected that more meditation education programmes will be developed and taught in schools.

Are schools the right place to teach meditation? From the standpoint of maximising reach, the answer is clearly yes. Unlike other potential sites for intervention, ${ }^{1}$ schools have contact with large numbers of children on a regular basis and across their formative developmental

\footnotetext{
${ }^{1}$ We do not advocate that meditation should be exclusively taught in schools, and we encourage meditation to also be introduced to children through their families and other social groups (e.g. sporting teams, youth groups, church).
} 
Table 1 Summary of meditative practices

Meditation practice Intention of the practice

Acem

Centering prayer

Loving kindness meditation

Mindfulness

Mindfulness-Based Stress

Reduction Programme (MBSR)

Shamatha

Transcendental meditation

Vipassana

Yoga Nidra

Zen
Thoughts, memories, emotions and sensations emerge and pass through the objective awareness of the practitioner, without any volitional attempt to control the content

A method of silent prayer that prepares the practitioner to receive the gift of contemplative prayer, prayer in which the recipient experiences God's presence within them

Deliberately focussing attention on positive feelings such as compassion, warmth and care for self and others

Deliberately focussing attention in the present moment, without judgment, to the experience that unfolds (Kabat-Zinn, 1990); attentional faculty comprising of continuous attention to an object without forgetfulness or distraction (Wallace 2006)

An 8-week group programme utilising various forms of mindfulness meditation including breath awareness, body scan exercises, walking and eating meditations and hatha yoga (Kabat-Zinn, 2003)

Placing attention on a mental image or visual object to attain attentional stability, vividness and introspection (10 stages of attentional development)

Silently repeating a word or mantra to achieve a meditative state. When distracting thoughts arise, attention is repeatedly redirected back to the mantra

Non-attached observation of bodily sensations and thoughts. Awareness is repeatedly redirected to the breath in the face of mental distractions

Attention is withdrawn from wishing to act and deployed towards sensory stimulation or imagination, while maintaining neutral observation of experience

Focussing attention on a word puzzle or breath awareness to exclude mental distractions and reach a heightened state of consciousness

Meditative practices are presented in alphabetical order

years where lifelong habits may be established. A key purpose of schools is to cultivate learning in young people and, according to Davidson and Lutz (2008), "the mental training of meditation is fundamentally no different than other forms of skill acquisition" (p. 176). Davidson and Lutz's (2008) research also shows that meditation can induce plasticity in the brain that assists learning. Finally, meditation education aligns with the twenty-first century notion of schooling which views learning as a holistic process that seeks to educate students academically, emotionally, socially, ethically and spiritually (Clonan et al. 2004).

However, given that many school curriculums are already over-crowded (Seldon, 2011), meditation should only be introduced if it is going to positively contribute to students. Research is a much needed way of assessing if meditation results in positive student outcomes. Yet, the Garrison Institute (2005) review of CE argued that "few school-based contemplative programs reflect research" (p. 43). This argument is also evidence in the review of Meiklejohn et al. (2012) of youth mindfulness programmes where only $60 \%$ of the programmes had been 
evaluated and published in peer-reviewed journals. Moreover, within that $60 \%$, there had only been one study conducted per programme, typically a pilot programme. As such, while meditation education programmes are on the rise, their design and implementation have not been supported by adequate research. In order to ensure that meditation is a sustainable educational pedagogy, solid research is needed. As such, it is time for a systematic review of research investigating teaching meditation in schools.

To date, research on youth meditation has focused largely on the therapeutic benefits of meditation in clinical youth samples or "at-risk" youth (Thompson and Gauntlett-Gilbert 2008; Zylowska et al. 2008). Typical outcome variables include depression, anxiety and anger management (Bögels et al. 2008; Singh et al. 2007). This small body of research shows that meditation is able to assist ill, troubled and disordered youth to manage their negative symptoms. For example, the review of Meiklejohn et al. (2012) focused on one meditation practice, that of mindfulness and the evidence of mindfulness as it related to outcomes for youth in clinical samples (e.g. youth with attention deficit hyperactivity disorder, obsessive compulsive disorder and autism spectrum disorder), residential care programmes (e.g. youth in substance abuse treatment programmes), paediatric and adolescent hospital patients (e.g. youth infected with HIV/AIDS) and schools. Their review offers a convincing rationale for the introduction of mindfulness to youth in clinical and at-risk populations.

However, non-clinical youth populations may also benefit from meditation where therapeutic intervention is not the focus. In non-clinical youth samples, school-based meditation would be beneficial if it assisted students to achieve the desired outcomes of schools such as academic-social-emotional learning. Hence, the overarching question that we seek to explore in this review is "What is the effectiveness of meditation in mainstream schools?"

To answer this question, we must clearly articulate what effectiveness means for mainstream students and provide a framework for understanding the mechanisms through which meditation influences key outcomes. With respect to defining effectiveness, we take a "whole student" approach and focus on scholastic outcomes as well as well-being and social outcomes. Evidence regarding the ways in which school meditation programmes assist wellbeing, social competence and academic achievement is reviewed. Further, an exploration of how meditation provides benefits to students is undertaken, and the School-Based Meditation Model is presented. Finally, the paper provides suggestions for future research.

\section{The Effects of School Meditation Programmes on Schooling Outcomes}

The following section will review evidence from 15 studies, which have investigated the evidence of meditation in schools. To qualify for review in this paper, the study had to meet three key criteria. First, the study had to be peer-reviewed and published in academic journals that are part of the Web of Science database and, thus, have already withstood the scrutiny of the peer review process. Second, the study had to be implemented with students at school rather than youth well-being programmes run in other settings (e.g. clinical settings or community settings). Third, the study had to be evaluated using valid and reliable research designs and measures. While the ideal design is randomised controlled experimental trials, we also accepted studies that had used quasi-experiment designs, provided that they had used pre-existing psychometrically established surveys and appropriate statistical analysis procedures. In these studies, we have discussed threats to external and internal validity when forming our conclusions as to whether meditation education assists student success. 
We also included qualitative studies and applied Miles and Huberman's (1994) test of "confirmability". In qualitative research, confirmability is likened to the test of validity used in quantitative analysis. Miles and Huberman (1994) argue that qualitative analysis is "confirmable" if it is credible, defensible, warranted and able to withstand alternative explanations. The inclusion of qualitative studies adds an important dimension to our review of the effects of meditation because they help researchers and educators to more deeply understand student experiences of meditation (Langdridge 2004). Qualitative methodologies explore narratives (rather than test predictions about variables) and look for participant defined meanings (rather than impose the researcher meaning) (Willig 2008). The lived experience of students in the meditation research, as collected through testimonials, provides richer descriptions of the underlying processes of meditation.

The aim was to report on evaluations that have been implemented across junior, middle and senior schools, across different school systems (e.g. public schools and private schools), in different countries, with students of both genders and various races (see Table 2).

In order to gain an understanding of the impact of meditation on student outcomes, we calculated the effect size (ES) by computing the standardised mean difference (i.e. Cohen's $d$ ) from the published data. ES computations were conducted using the Comprehensive MetaAnalysis software program, v. 2.2 (Biostat, 2011).

Three studies were qualitative, and two studies reported insufficient statistics; thus, ES could not be calculated for five of the 15 studies under review. Of the remaining 10 studies, the overall number of participants in the effect size analyses was 1,797. Where available, the means and standard deviations (SD) of the intervention and control groups were used to compute $d$. If these statistics were not available, alternate methods, such as using the $t$ or $F$ statistic, were employed. ES estimates were attempted for all studies even if the publication already reported a Cohen's $d$ value, to ensure that consistent formulas were used in the calculations. According to Cohen (1988), small, medium and large effects, respectively, are $0.2,0.5$ and 0.8 . For more information about the calculation of ESs in this review paper, see Appendix 1.

In addition to Cohen's $d$ effect sizes, we assessed the percentage of significant findings across the following meditation programme characteristics: meditation type, duration of the programme, frequency of sessions, age of the student sample and the person who delivered the programme. Given the small number of studies, lack of measurement information (e.g. reliability) and differences in measurement and construct properties, we were unable to meta-analytically combine the effect sizes to run moderator analyses (e.g. Hunter and Schmidt 2004). Instead, we calculated the percentage of significant effects for each of the programme characteristics to form tentative ideas regarding the extent to which the key outcomes are impacted by programme characteristics (Table 3 ).

For ease of interpretation, the five elements were divided into several categories. The type of meditative practice was categorised into one of three types: $1=\mathrm{TM}(35 \% ; k=6), 2=$ mindfulness-based programmes $(35 \% ; k=6)$ and $3=$ other (e.g. attention-focussed programmes, Tia Chi, yoga) $(29 \%$; $k=5)$. Programme duration was divided into three lengths: $1=6$ weeks or less $(29 \% ; k=5) ; 2=6-24$ weeks $(35 \% ; k=6)$ and $3=>24$ weeks $(35 \% ; k=6)$. Three categories were made for session frequency: $1=$ more than once daily at school $(40 \%$; $k=6) ; 2=$ daily at school $(20 \% ; k=3)$ and $3=$ weekly $(40 \% ; k=6)$. With respect to age, the studies were divided into one of four categories: $1=$ elementary school $(5-10$ years $)(29 \%$; $k=$ 4); $2=$ middle school $(10-13$ years) $(36 \% ; k=5) ; 3=$ high school $(13+$ years $)(36 \% ; k=5)$ and $4=$ whole school studies $(21 \% ; k=3)$. The categories for person who delivered the programme were $1=$ teacher $(57 \% ; k=8)$ and $2=$ other (researcher, psychologist, meditation practitioner) $(43 \% ; k=6)$. 


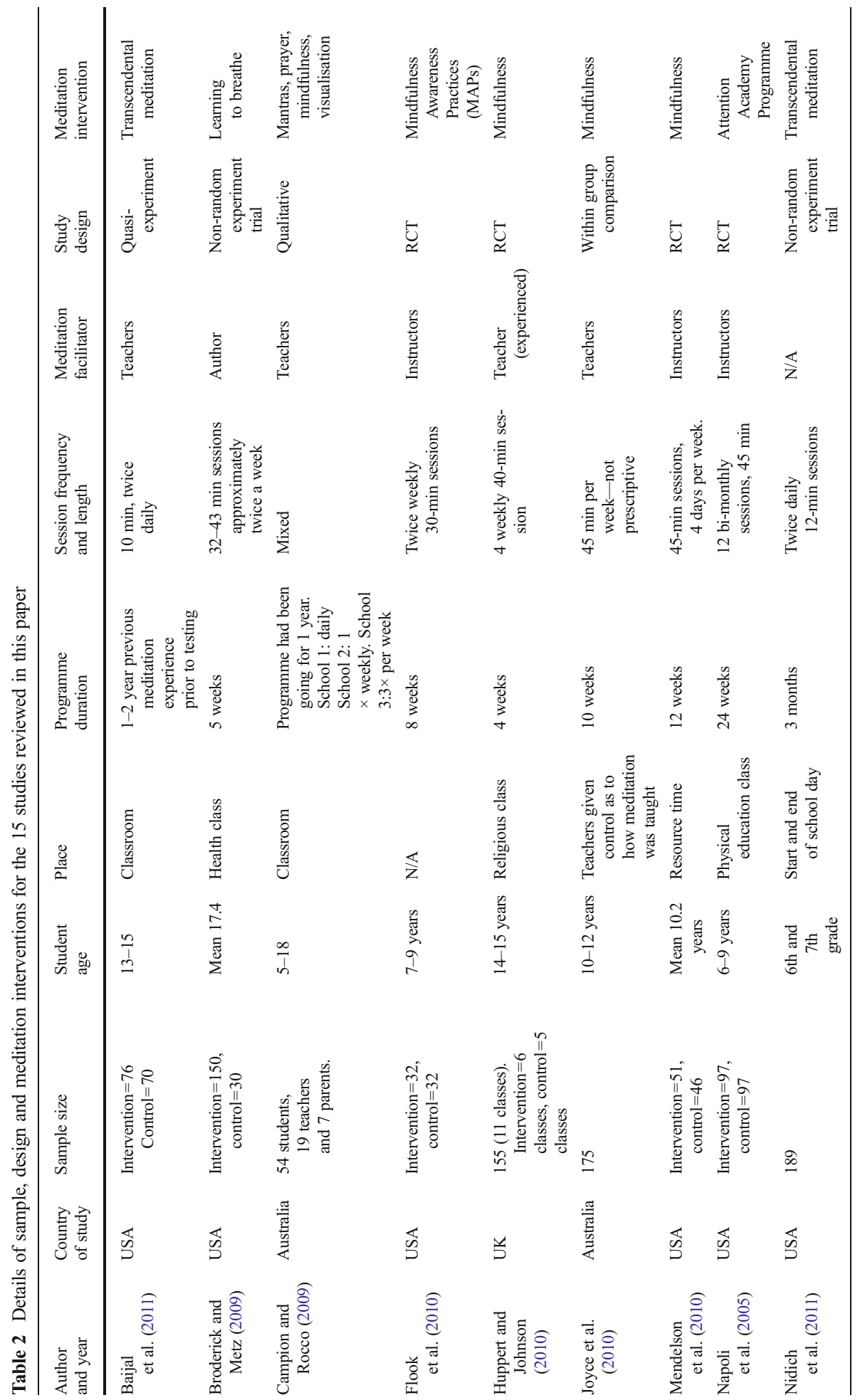




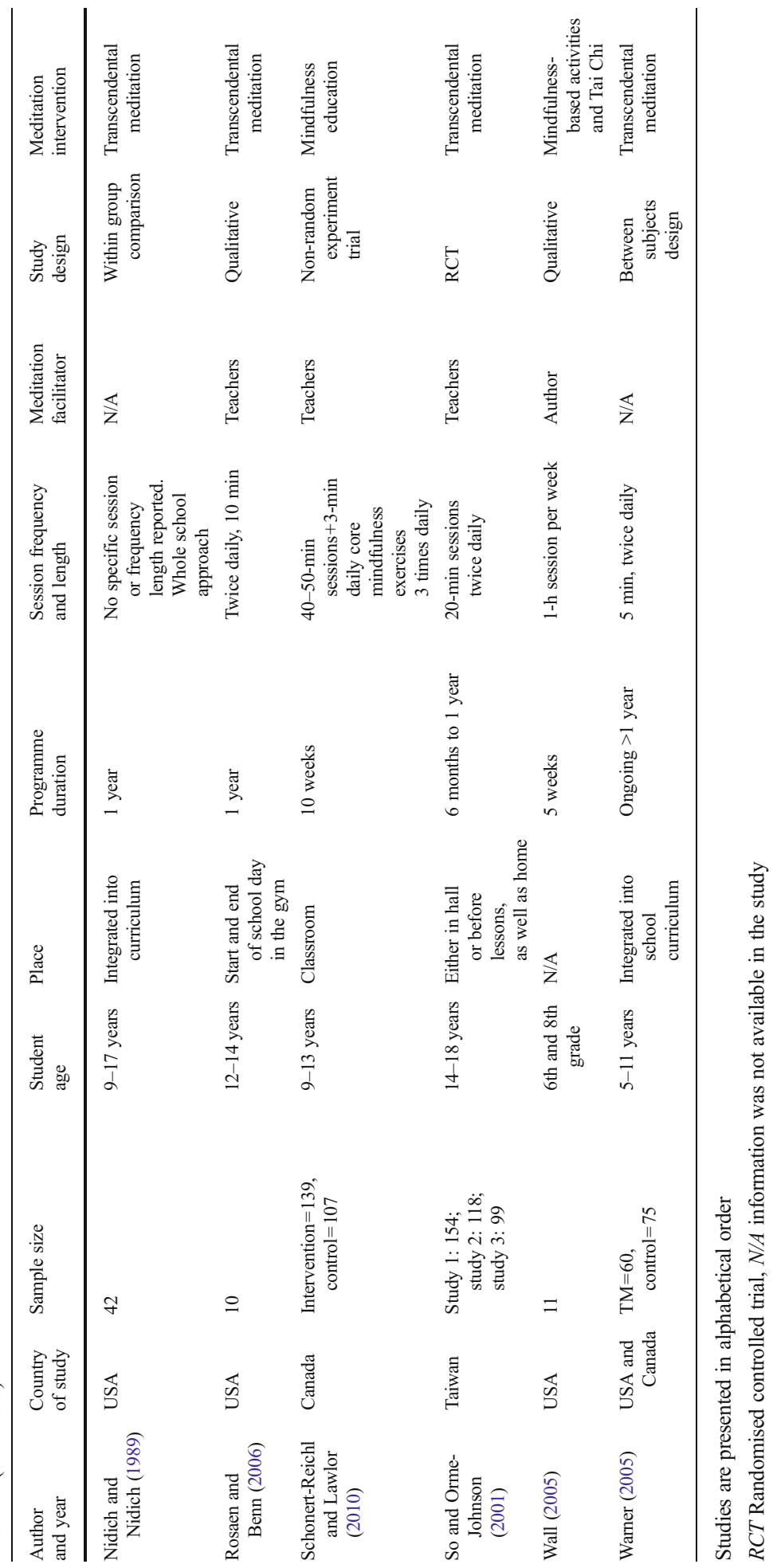




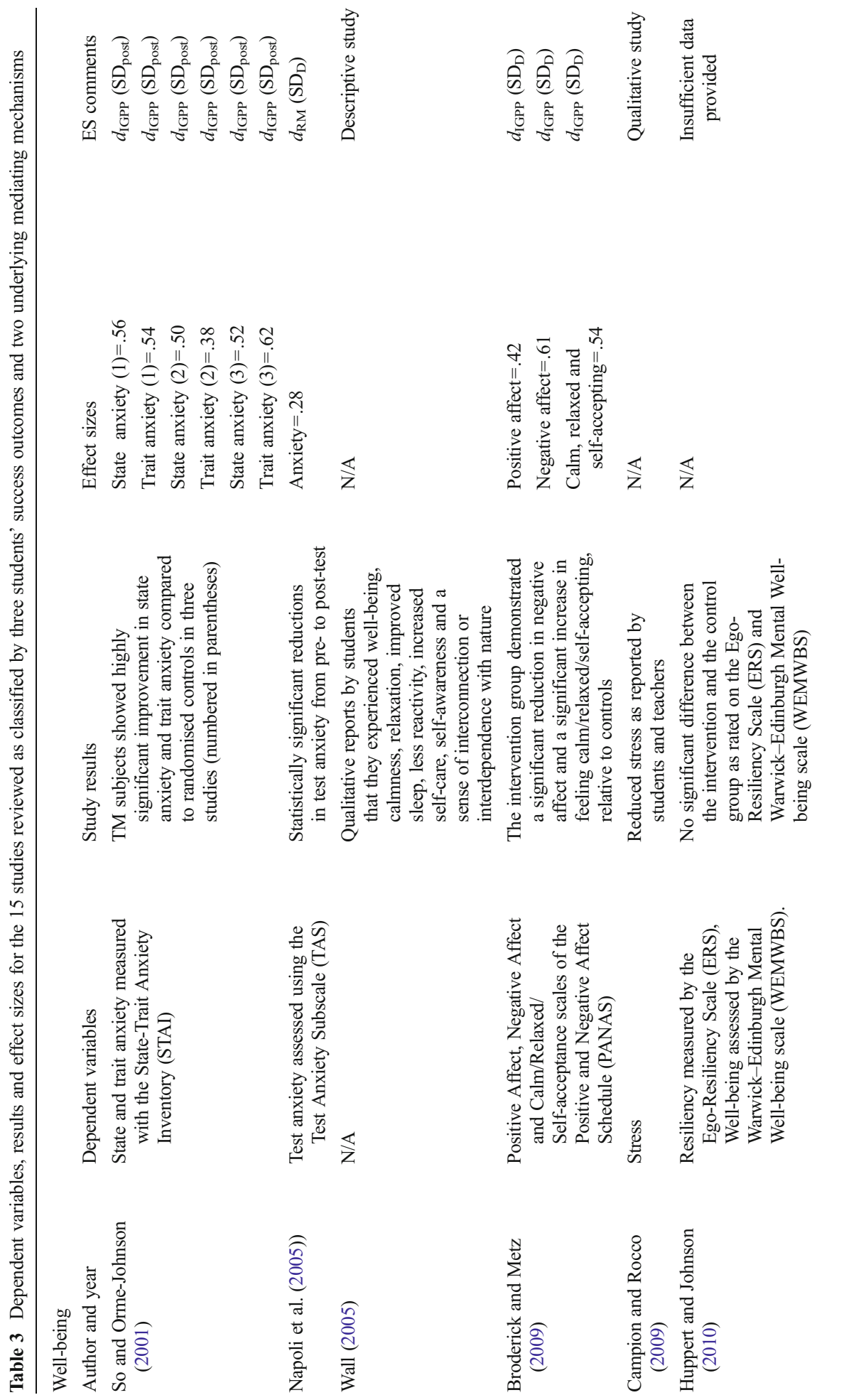




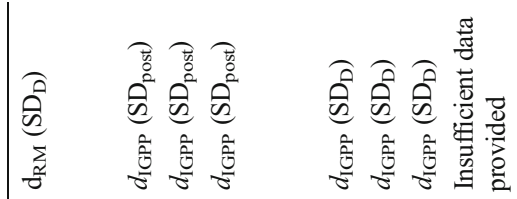

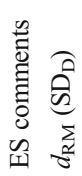

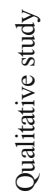

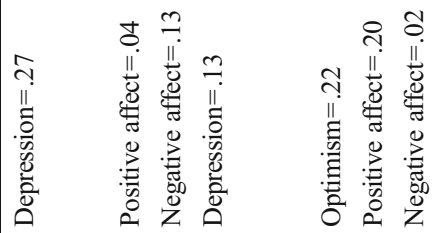

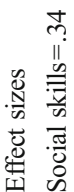

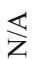

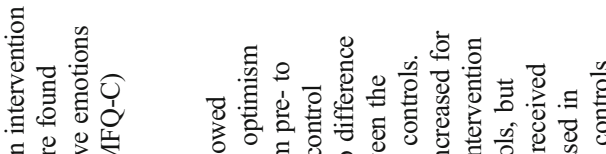

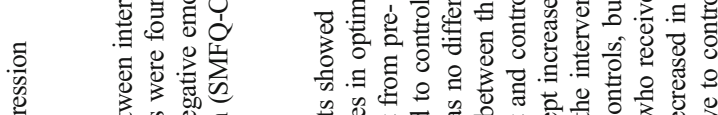

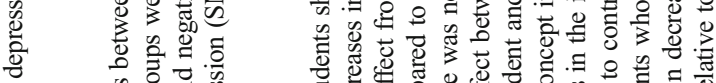

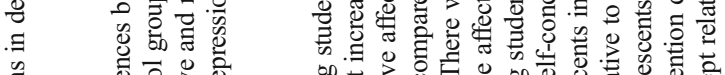

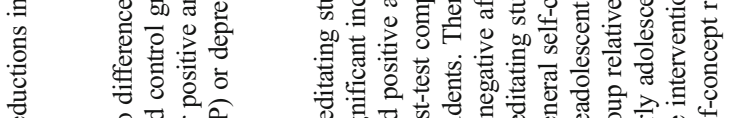

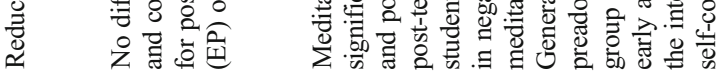

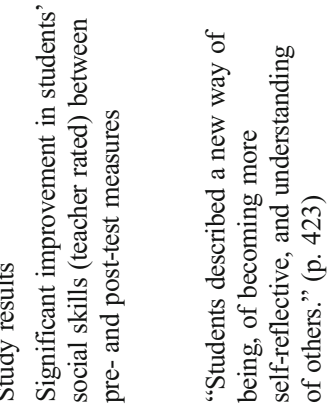

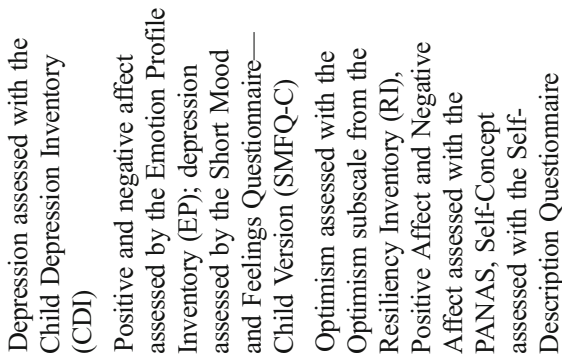

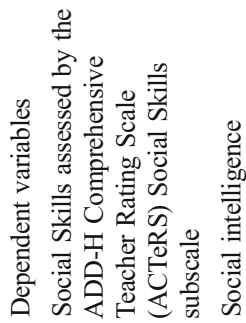

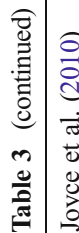
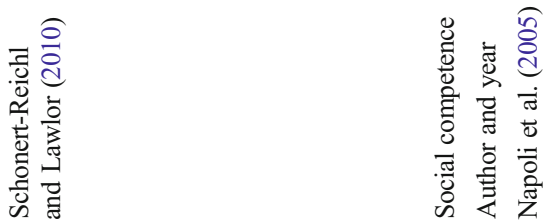

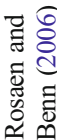



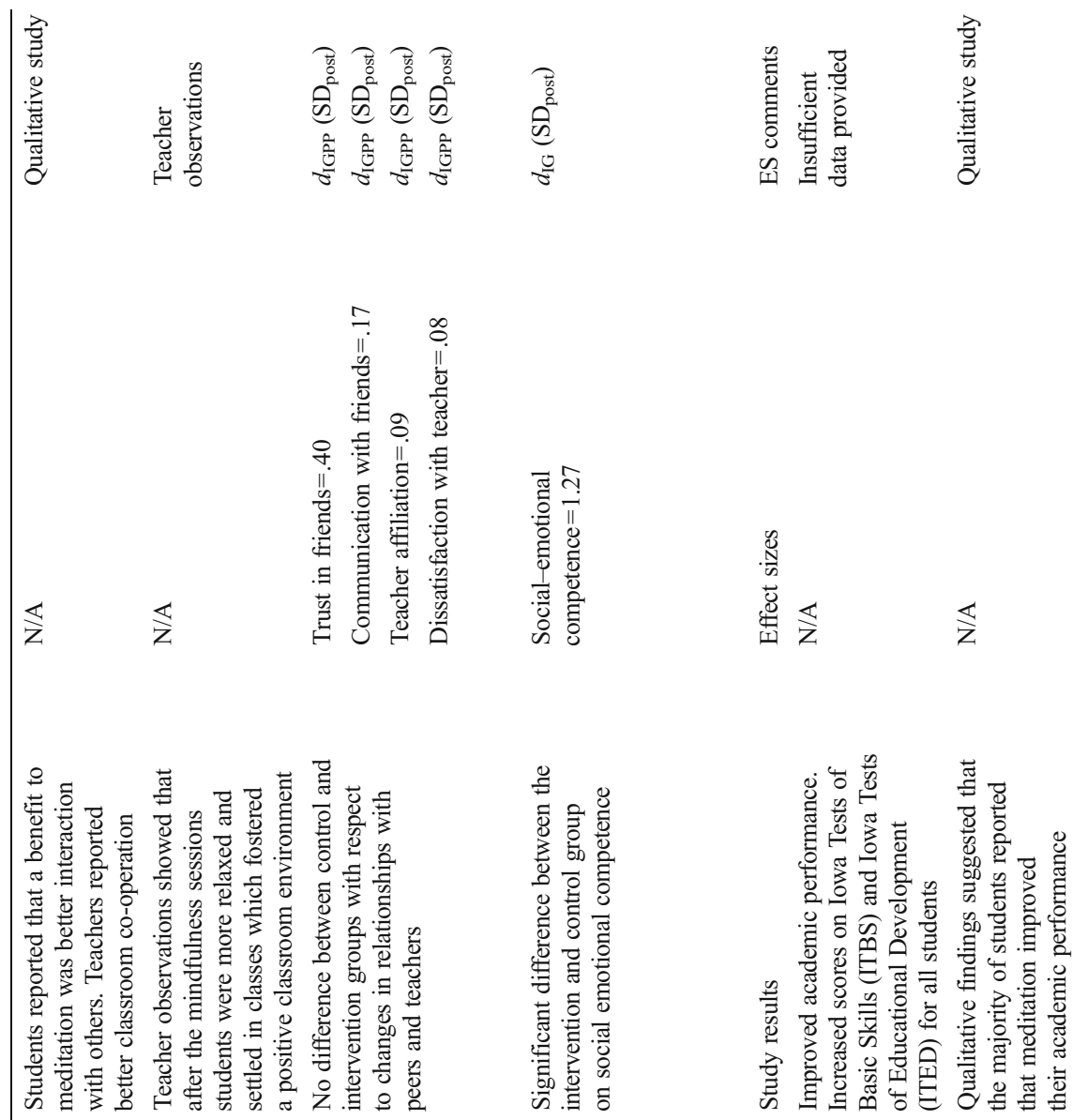

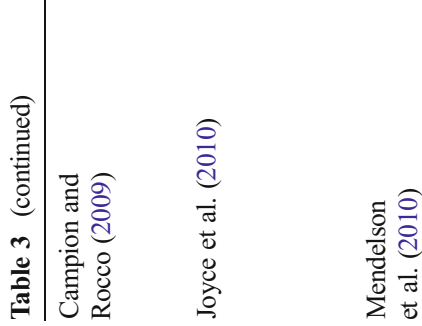
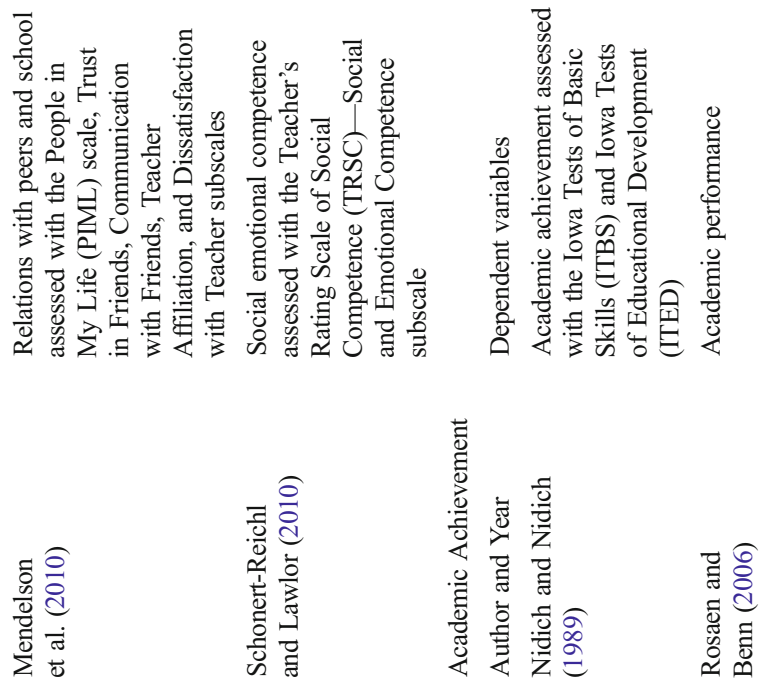


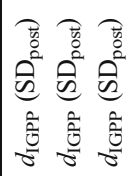

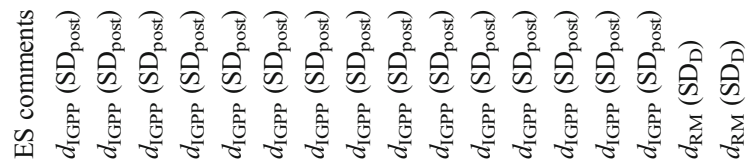

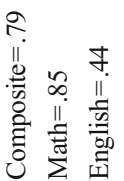

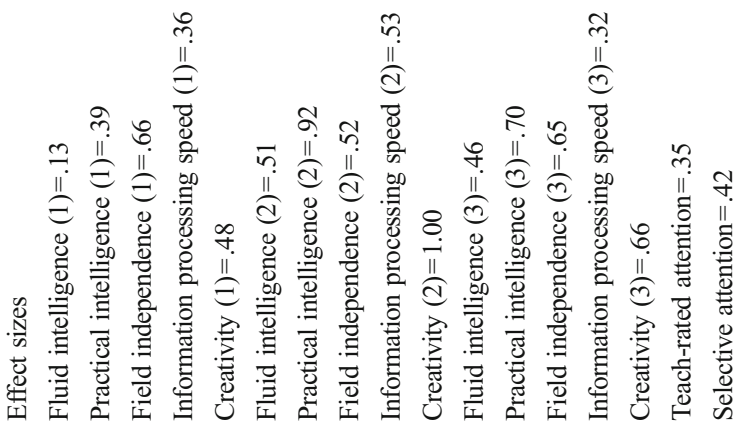

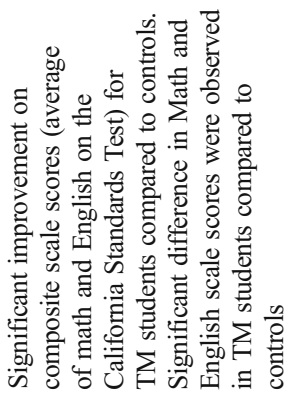
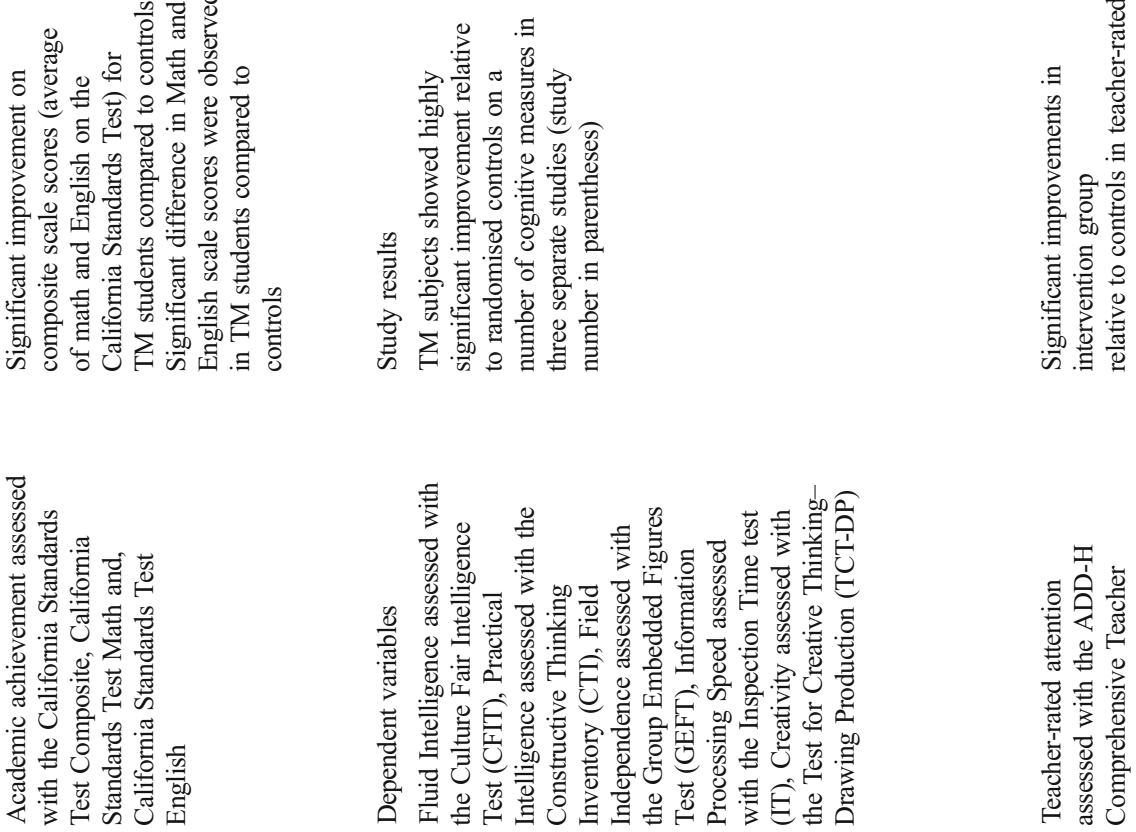

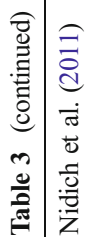
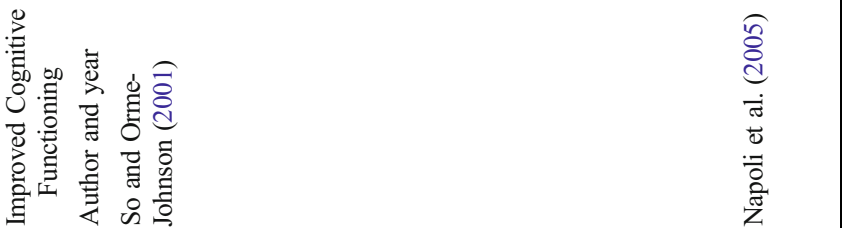


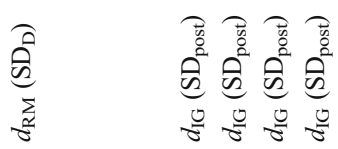

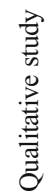

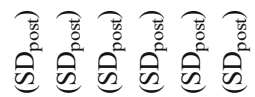

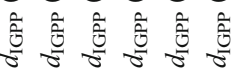

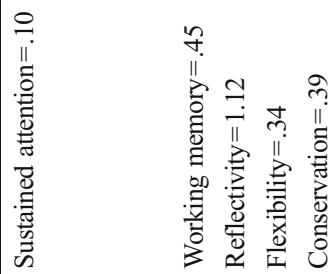

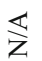

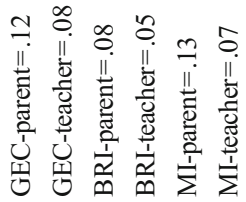

फे

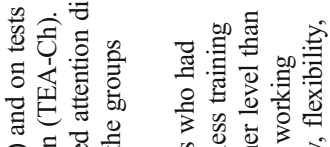

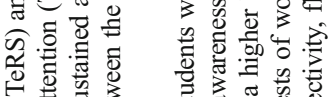

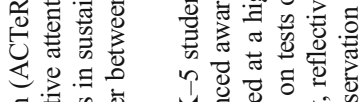

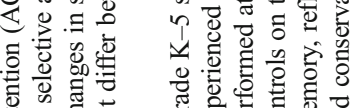

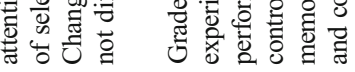

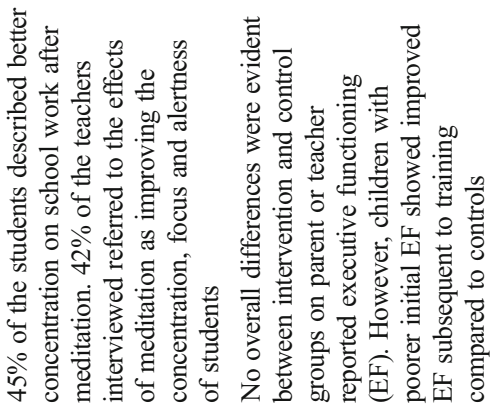

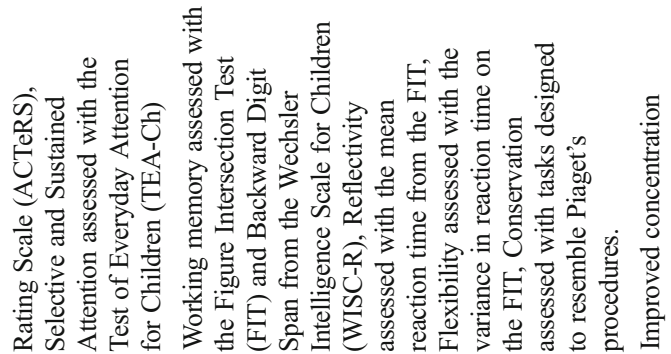

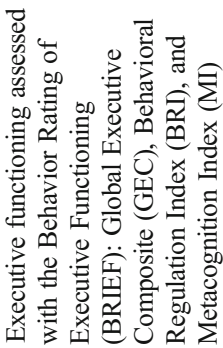

总

六

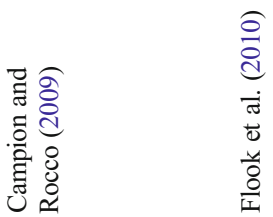

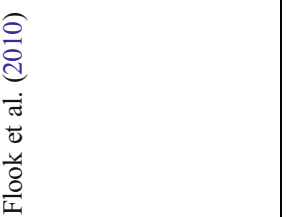



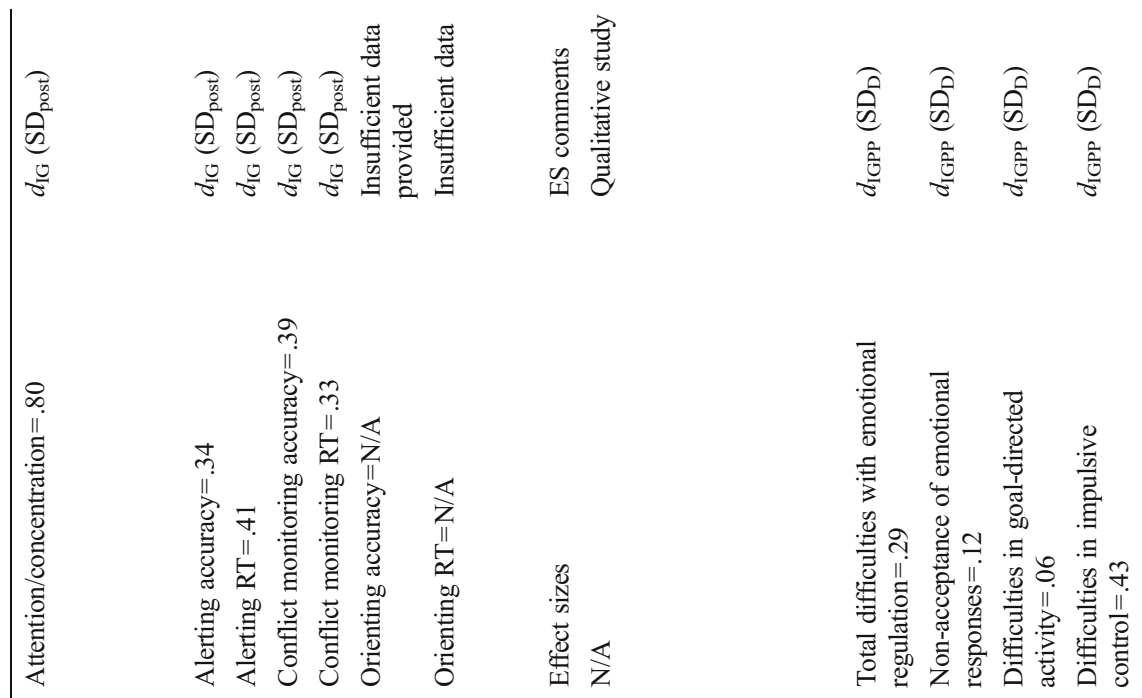

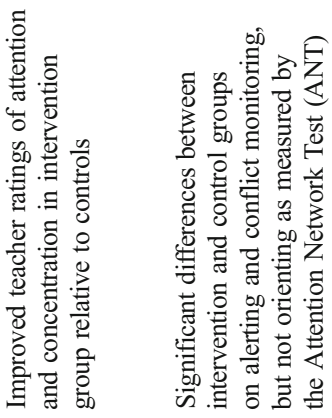

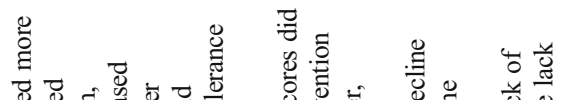

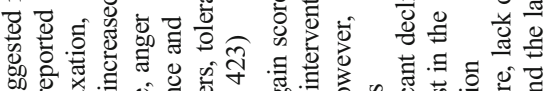

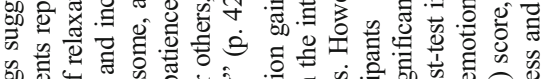

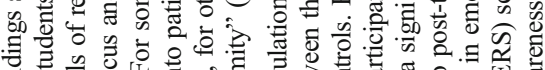

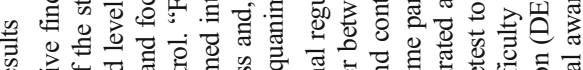

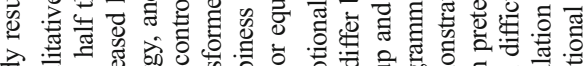

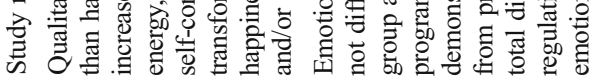

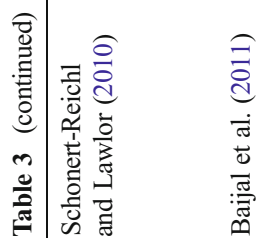
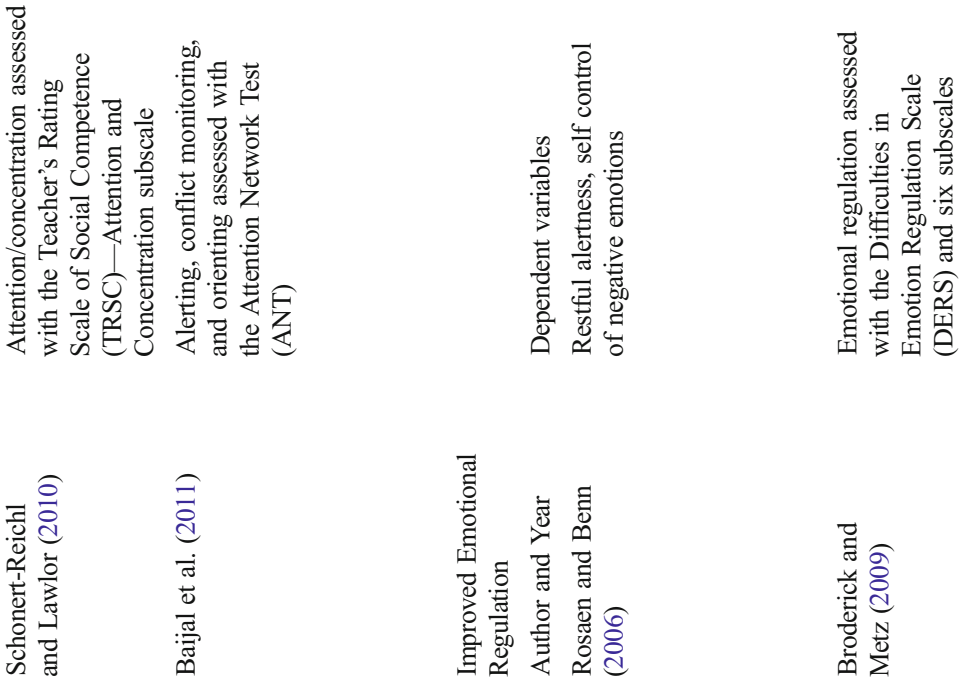

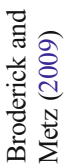




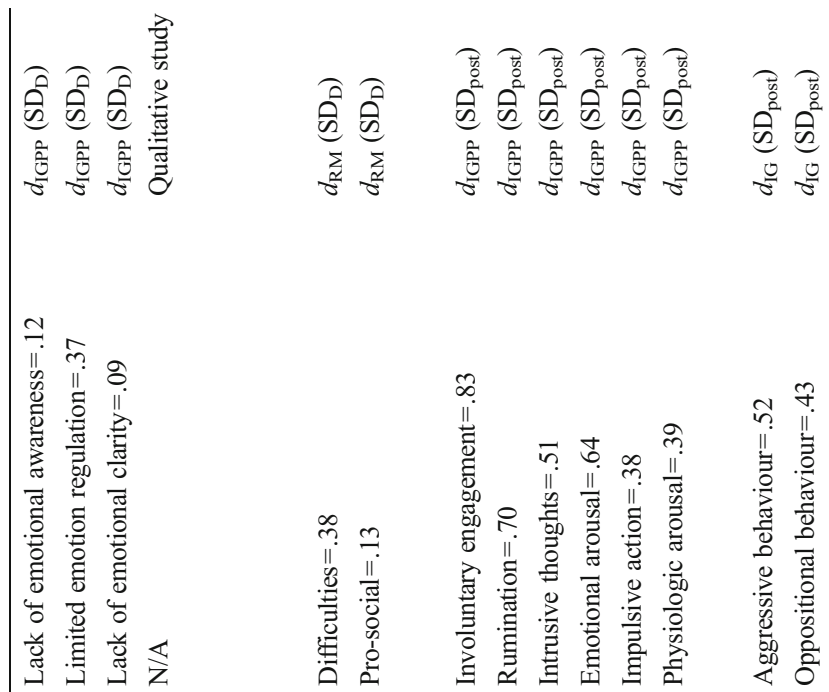

की छี

छ. ڤ क

至 焉 क

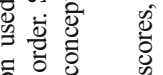

를

要

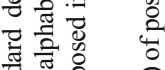

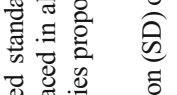

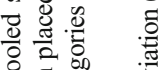

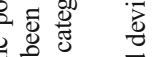

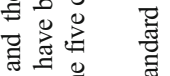

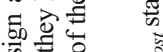

ชै हैं

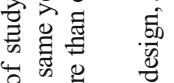

范

है है

웡

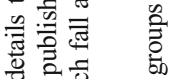

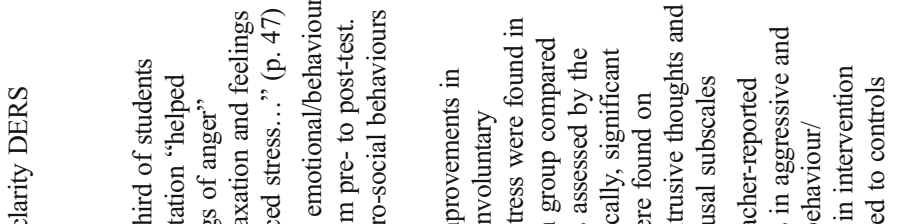

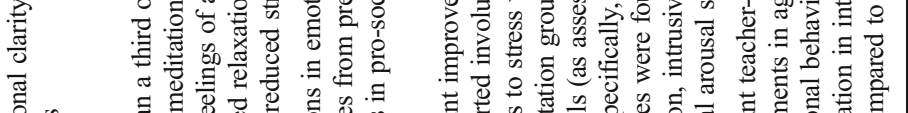

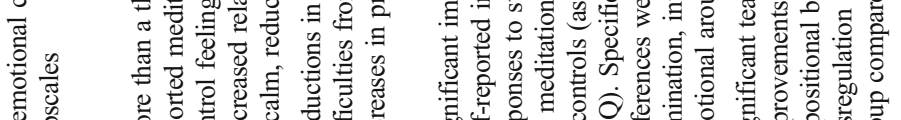

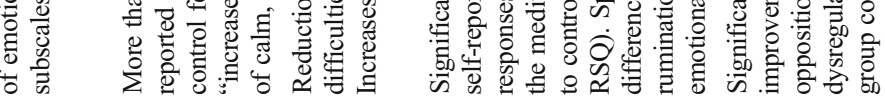

总

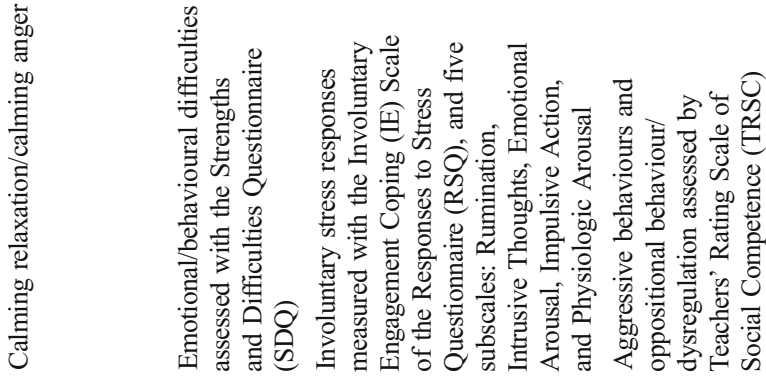

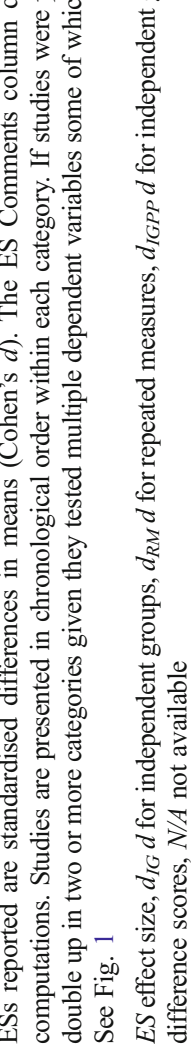


Each study provided between 1 and 17 effects for a total of $76^{2}$ effects of which $61 \%$ were significant. Below, we detail the findings of the studies and provide the effect sizes for each result according to the three student outcomes of well-being, social competence and academic achievement.

\section{The Effects of Meditation Programmes on Well-being}

Student well-being has become a key agenda for schools, and many now consider it an educational outcome that is of equal importance to academic achievement (Seligman et al. 2009; Waters 2011). The effects of school meditation have been examined in relation to numerous aspects of well-being, including student anxiety, stress, depression, optimism, positive affect, self-concept, self-care and self-acceptance. We obtained nine studies $(n=$ 1,483 ) investigating the influence of meditation upon well-being. The 9 studies provided 17 results, ${ }^{3}$ and of these, $59 \%$ were significant. Cohen's $d$ ranged from 0.02 to 0.62 with $65 \%$ of the effect sizes being small and $42 \%$ medium.

Using a combination of mindfulness and body scanning practice on first and third graders, Napoli et al. (2005) found significant reductions in self-reported anxiety for the intervention group $(n=97)$ from pre- to post-test compared to controls $(n=97)(d=.28)$ who were engaged in quite reading and other quiet activities. ${ }^{4}$ Similarly, So and Orme-Johnson (2001) found significantly lower state anxiety and trait anxiety in high school students following a TM meditation intervention compared to the napping and no interest group. Both studies show clear reductions in negative emotional outcomes from treatment to control groups and that the effect of meditation goes above and beyond simply "un-plugging" or engaging in restful activity.

Broderick and Metz (2009) also found the mean scores of students in a mindfulness meditation condition showed significant reductions in negative affect $(d=.61)$ compared to a non-equivalent control group. Similarly, Joyce et al. (2010) found that the number of 10- and 13 -year-old children who were categorised at pre-test into the "borderline" and "abnormal" categories of emotional problems and depression significantly decreased at the post-test following 10 weeks of mindfulness meditation. Finally, using semi-structured interviews of students, Campion and Rocco (2009) found that students who meditated reported reductions in stress. Additionally, $48 \%$ of students mentioned that learning meditation at school had led them to practice meditation outside of school when they were stressed.

However, significant improvements in hedonic states were not uniformly observed. Mendelson et al. (2010)) detected no differences between the randomly assigned meditation group and control group of fourth and fifth graders in positive affect or negative affect following 12 weeks of mindfulness meditation. However, at post-test, students who underwent the intervention scored significantly lower on emotional arousal $(d=.64)$, intrusive thoughts $(d=.51)$, involuntary engagement $(\mathrm{d}=.83)$ and rumination $(d=.70)$, suggesting that while mood was unaffected, general stress and coping responses were improved. The qualitative findings collected in this study supported the quantitative findings that meditation reduced stress. For example, a fourth grade student commented, "now I know different routines and exercises that I can do at home that helps me lower and reduce my stress."

\footnotetext{
${ }^{2}$ When comparing groups, we restricted our comparisons to groups that contained at least three effects to avoid the distortion of percentages that occurs with very small samples.

${ }^{3}$ Three studies were qualitative, and two studies did not provide sufficient data for effect sizes to be calculated.

${ }^{4}$ For full details of the study design, see Table 2.
} 
A number of studies have investigated the promotion of positive affective states and wellbeing rather than the reduction in negative well-being outcomes although the results are decidedly more mixed. Schonert-Reichl and Lawlor (2010) evaluated the influence of a 10lesson mindfulness education (ME) intervention and found that students in the ME intervention showed small but significant improvements in optimism $(d=.22)$ and positive affect $(d=.20)$ compared to controls. In contrast, while general self-concept increased for preadolescents (fourth and fifth graders) in the ME group compared to those in the control group, the opposite was seen for early adolescents. Similarly, Huppert and Johnson (2010) found that no strong group differences were detected in terms of resilience or psychological well-being in 14-16-year-old boys who were randomly assigned to four times 40-min mindfulness training sessions versus a control condition. However, within the meditation group, increased meditation practice outside the classroom was significantly related to self-reported improvements in wellbeing. Wall (2005) found that students reported improvements in well-being, calmness, relaxation, sleep, reactivity, self-care and self-awareness, as well as a sense of interconnection with nature as a result of the programme following five, hour-long sessions combining MindfulnessBased Stress Reduction (MBSR), Tai Chi exercises and the use of Koans (i.e. traditional Japanese Zen meditation questions/puzzles/stories). Similarly, Rosaen and Benn (2006) interviewed seventh-grade racial minority students who had practiced TM for over a year in a qualitative evaluation. Students reported greater emotional regulation, including self-reflection, self-control and levels of restful alertness, in addition to reductions in stress. Comments include, "It's made me a calm person and easier to talk to, and listen to other people."

In summary, the findings provide tentative conclusions with respect to the effectiveness of meditation programmes on student well-being. The overall profile suggests that meditation fosters small improvements in well-being. The benefits are more consistent for reducing negative rather than promoting positive outcomes. However, we could locate only a small number of studies investigating positive outcomes, which reflects, in part, a greater focus within the psychology literature on illness rather than wellness outcomes (Seligman and Csikszentmihalyi 2000).

The evidence to date shows that TM has more consistent significant effects on well-being ( $83 \%$ of effects were significant; $n=6^{5}$ ) in comparison to mindfulness $(44 \% ; n=9)$ and other meditation techniques $(42 \% ; n=7)$. Programmes that went for a longer duration (i.e. longer than 24 weeks) tended to have more consistent significant findings with $83 \%(n=6)$ of the interventions that were more than 24 weeks reported as significant while only $38 \%(n=8)$ of interventions that lasted between 6 and 24 weeks being significant. Curiously, $50 \%(n=4)$ of the interventions that were shorter than 6 weeks had significant effects. More frequent meditation generated more significant findings among well-being variables, with practice of more than once per day showing significance $67 \%(n=9)$, while daily practice was significant $40 \%(n=5)$ and weekly practice $50 \%(n=8)$. The age of the participants appeared to matter as well, with senior school students showing more consistent efficacy $(64 \% ; n=14)$ in comparison to middle school $(25 \% ; n=4)$ and $\mathrm{K}-12$ schools $(33 \% ; n=3)$. Finally, interventions delivered by teachers showed substantially more consistent effects $(75 \% ; n=12)$ than other instructors $(30 \% ; n=10)$.

\section{The Effects of Meditation Interventions on Social Competence}

Social competence has become a key outcome of schooling in the twenty-first century, and new curriculums are being developed to enhance social skills in students (Bernard and Walton

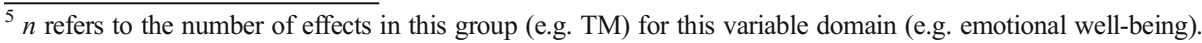


2011; Seligman et al. 2009). In broad terms, social competence may be seen as a multidimensional construct, encompassing skills and behaviours that enable successful functioning within social contexts (Beauchamp and Anderson 2010; Waters and Sroufe 1983). A critical component of social competence is the ability to balance personal desires with maintaining positive social relationships (Green and Rechis 2006; Rose-Krasnor 1997). Social competence is recognised as an essential element in childhood development, underlying long-term interpersonal outcomes, emotional and behavioural adjustments, psychological functioning and academic skills (Burt et al. 2008; McClelland et al. 2006; Robinson et al. 2013). We located six studies investigating the effects of meditation on indicators of social competence reporting a total of 776 participants. We observed six effect sizes of which $33 \%$ were significant with Cohen's $d$ ranging from 0.08 to 1.27 . The majority of the effects sizes upon social competence were small $(83 \%)$ and $17 \%$ of the effects were large.

With respect to increased pro-social behaviour, Schonert-Reichl and Lawlor (2010) observed significant, strong improvements in a range of teacher-reported social-emotional competence $(d=1.27)$ from pre- to post-test in the ME group compared to controls. With respect to reducing anti-social behaviour such as students disrupting one another and disobeying the teachers, the teacher observations of Joyce et al. (2010) showed that, after the mindfulness sessions, students were more relaxed and settled in class. In addition, teachers from the study of Napoli et al. (2005) reported fewer attention deficit hyperactive behaviours in class in those students who had undertaken meditation compared to the control group $(d=$ $0.35)$.

Qualitative research supports the general findings from the quantitative studies with respect to the social outcomes. In Campion and Rocco's (2009) qualitative exploration of the effects of a year of mindfulness, students reported that the mindfulness techniques assisted them with anger management, which helped them to have better friendships and more positive interactions with others. This outcome was verified by the teachers, who reported that they had fewer fights to attend to in the schoolyard. One teacher commented, "I found straightaway...they deal better with each other than other times." Twenty-six per cent of teachers in Campion and Rocco's (2009) study also reported that the mindfulness programme fostered more positive classroom behaviours. Similarly, in Rosaen and Benn's (2006) qualitative study, students reported that meditation had helped them to be more socially skilled and to calm their antisocial tendencies. One student commented, "Like, I'm more nicer and mature...Like I can listen to them." Another student reported "If I meditate, I feel calm and feel like I don't have to argue with anybody."

In summary, significant, but predominantly small, effects for meditation were found upon social competence. The only meditation intervention characteristic that had enough effects to compare different practices was the type of facilitator. ${ }^{6}$ A higher percentage of interventions were found where the teacher was the facilitator $(75 \% ; n=4)$ compared to other instructors $(20 \% ; n=5)$.

\section{The Effects of Meditation Interventions on Academic Achievement}

Despite the popular claim that meditation assists academic achievement (Wickelgren, 2012), the study of the effects of meditation upon academic achievement has received scant research

\footnotetext{
${ }^{6}$ The percentage of significant effects for the other programme characteristics (e.g. programme duration, frequency, age etc.) were not calculated because, in all cases, there are two or fewer effects in the comparison groups except for facilitator.
} 
attention. To date, only three studies have investigated the relationship between meditation and academic performance. Two studies used differences in standardised academic tests, and the third used subjective student self-assessments of academic achievement. Effect sizes were only able to be calculated for two of the three studies. Cohen's $d$ for academic achievement ranged from 0.44 to 0.83 . Fifty per cent of the effects were large, $25 \%$ were medium and $25 \%$ were small.

Using standardised tests as outcome variables, Nidich and Nidich (1989) and Nidich et al. (2011) provide the most evidence for positive impact of transcendental meditation (TM) programmes. Nidich and Nidich (1989) examined the impact of 12-min sessions of TM on academic achievement and found that third to seventh graders demonstrated an increase in reading, vocabulary, language and study skills, while ninth to 11th graders improved on social studies, literary materials, reading and quantitative thinking skills on ITBS and Iowa Tests of Educational Development tests. Nidich et al. (2011) reported strong significant improvements in English and Math scores on the California Standards Test for 125 sixth- and seventh-grade students who underwent 3 months of twice daily (i.e. before and after school) 12-min TM practice in comparison to a randomly assigned control group. Students in Rosaen and Benn's (2006) study self-reported improvements in academic performance and attributed this to their increased capacity for "restful alertness" brought about by meditation.

In summary, research into school meditation programmes is still in its infancy, and only three published studies have examined the relationship between meditation and academic achievement. Insufficient evidence has yet to be accumulated to answer the question, "What is the effectiveness of meditation in mainstream schools in relation to academic achievement?"

\section{Why Does Meditation Influence Student Outcomes?}

In the previous section, we considered meditation in relation to three aspects of student success and found that the majority of meditation programmes have a significant, albeit small, effect on well-being and social competence. For academic achievement, there has simply not been enough research to warrant any conclusions. To guide further work in this area and to enhance the effectiveness of meditation interventions in schools, a conceptual model for understanding the underlying mechanisms through which meditation impacts student outcomes is needed. To this end, the following sections draw on the evidence showing that meditation creates brain changes which foster two key abilities important for a student's schooling success: (1) cognitive functioning and (2) emotional regulation. These two functions assist students to learn, plan, engage in goal directed activity, handle their own emotions and behave appropriately - and are heightened through meditation. Teaching in ways that develop these two functions also has long-term benefits for students beyond school life. Long after a student has forgotten the algorithms taught in ninth grade, they will still make use of cognitive functioning skills and emotional regulation skills. Figure 1 presents a conceptual model outlining the potential links between meditation, cognitive functioning, emotional regulation and the three student success outcomes reviewed above. The conceptual model gives rise to two key propositions.

Proposition 1 Meditation positively influences student success (well-being, social competence and academic achievement) by increasing cognitive functioning including attention, learning and memory in students.

Proposition 2 Meditation positively influences student success (well-being, social competence and academic achievement) by increasing emotional regulation in students. 


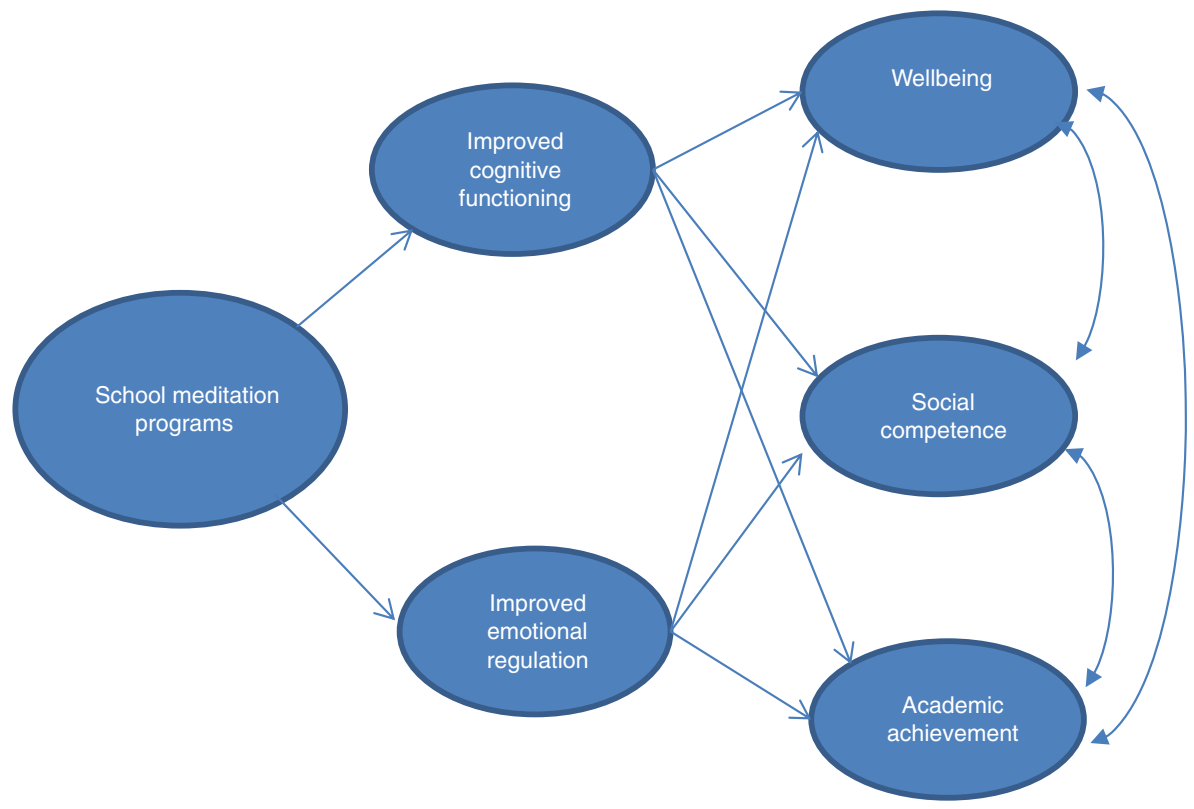

Fig. 1 'The School-Based Meditation Model'

The "School-Based Meditation Model" in Fig. 1 has been developed using three strands of research: first, research from education showing that cognitive function and emotional regulation are positively associated with well-being, social competence and academic achievement; second, adult neuroscience research showing associations between meditation and areas of the brain that are responsible for cognitive function and emotional regulation; and third, research from contemplative education showing that students who attend school meditation activities have increased cognitive function (e.g. better working memory) and increased emotional regulation (e.g. students and teachers report being better able to manage anger and stress) compared to control groups. Evidence for each of these strands of research will be outlined below.

The School-Based Meditation Model is a useful way to organise research being produced in the field of contemplative education. Currently, the literature is fragmented, and no model has been put forward to understand what happens to students "inner worlds" when they meditate. Instead, the research has focussed on outcomes rather than causal variables. The pathways in the School-Based Meditation Model are hypothetical, and given that there has been is no neuroscience research conducted in youth meditation studies, we cannot say for sure that meditation is affecting the brain (and therefore cognitive function and emotional regulation) in the same way that it has been shown to do in adults. Hence, an educated guess from the adult neuroscience research must be made to suggest that meditation can change the brain of students in ways that increase cognitive function and emotional regulation. This educated guess is supported by the evidence that school-based meditation programmes have found outcomes showing improved cognitive function and emotional regulation (Baijal et al. 2011; Schonert-Reichl and Lawlor 2010). Detailed evidence from the three strands of research that have been integrated to build the School-Based Meditation Model will be presented below. 


\section{Meditation, Cognitive Functioning and Student outcomes}

Cognitive Functioning and Student Outcomes Cognitive skills such as attention regulation, information processing speed, working memory, creativity, cognitive flexibility and meta cognition have all been shown to contribute to students' learning (Conway et al. 2002; Lan et al. 2011). Improved cognitive functioning is also a pathway to enhanced well-being. This is because attentional regulation and cognitive flexibility (i.e. the ability to inhibit automatic cognitive responses) are important skills in reducing automatic emotional reactivity (Lutz et al. 2008a, b). Furthermore, according to cognitive-behaviour theory, attentional processes and cognitive appraisals of events are determinants of one's emotions and behaviours. Specifically, those people who develop the cognitive ability to disengage their attention from a negative interpretation and re-orient their attention towards alternative, adaptive interpretations have higher well-being (Hanif et al. 2012; Wadlinger and Isaacowitz 2011). This has been supported in empirical research conducted with clinical and non-clinical samples. Clinical interventions that train depressed patients to more consciously engage their attentional networks so they become clearer of their negative thoughts are successfully utilised to reduce affective dysregulation (e.g. Siegle et al. 2007). In a non-clinical sample, Compton (2000) found that individuals with slower attentional disengagement experienced more negative affect in response to a distressing film clip compared to controls, suggesting that attentional regulation is an important predictor of well-being. Improved cognitive functioning is also related to social competence. Research has highlighted a relationship between social competence and cognitive abilities (Riggs et al. 2006). Longitudinal research by Ciairano et al. (2007) demonstrated that difficulty with executive inhibitory cognitive control was the most influential and stable predictor of non-cooperative behaviour in elementary school children. Ramos et al. (2013) found that preschoolers with lower cognitive scores in verbal, quantitative and memory domains also had lower teacher-reported social competence. Conversely, preschoolers with higher levels of nonverbal cognitive ability and language competence were rated as more socially competent than those with lower levels of nonverbal cognitive ability and language competence (Oades-Sese et al., 2011).

Meditation and the Neurological Substrates of Enhanced Cognitive Function Being in a meditative state has been shown to give rise to experiences of sustained concentration, heightened awareness, reduced mental noise, clarity of consciousness, meta-cognition, executive functioning, working memory and attentional blink (Dietrich, 2003). Indeed, research has shown that meditation induces changes in the prefrontal cortex, which oversees higher-level executive functions, including attention, concentration and emotional regulation (Cahn and Polich 2006; Davidson et al. 2003; Greeson 2009; Lutz et al. 2008a). Meditation has also been linked to brain wave states that foster attention and meta-thinking or integrated thought. For example, Aftanas and Golocheikine (2001) measured the electroencephalography (EEG) activity of 16 long-term meditators (minimum 3 years practice) and 11 short-term meditators ( $<6$ months practice) during a meditative state. Greater theta synchronisation in the anterior midline was observed in long-term compared to short-term meditators. Midbrain theta activity occurs during states of attentive arousal (Singer 1993) and reflects enhanced focussed attention (Aftanas and Golocheikine 2001).

Lutz et al. (2004) reported sustained high-amplitude gamma band oscillations and synchronisation in eight long-term Buddhist meditators compared to 10 controls during a loving kindness meditation. This pattern of brainwave activity is typically observed during states of focussed attention and is thought to reflect higher order cognitive processing (Singer 1993; Tallon-Baudry and Bertrand 1999), suggesting that a higher-order cognitive processes may be 
developed through meditation. The difference in gamma-band activity was also observed at baseline in experienced meditators, suggesting that the neural changes associated with meditation are observed beyond the meditation period.

An EEG study by Lagopoulos et al. (2009) observed a significant increase in theta activity in frontal and temporal brain regions and increased alpha activity in posterior regions during an acem meditation exercise compared to rest in 17 experienced meditators (minimum 9 years practice). While theta activity characterises an alert and attentive state, alpha activity is reflective of a relaxed state (Singer 1993), suggesting these people were relaxed but alert. Other studies have also reported particular brain wave amplitude and frequencies at the theta, alpha and gamma levels as reported in EEG studies, which support the finding that meditation is an effective attention training tool that develops neurological faculties supporting sustained attention (Kjaer et al. 2002; Lutz et al. 2004).

Different patterns of brainwave activation are associated with various states of arousal and levels of consciousness. In particular, theta oscillations are prominent in the midbrain area and occur around the 6-7 Hz range. This pattern of brainwave activity is observed during states of attentive arousal. Alpha oscillations occur in the $10 \mathrm{~Hz}$ range and occur during relaxing or drowsy states. Gamma oscillations are much larger in amplitude and occur in the $30-60 \mathrm{~Hz}$ range, usually reflecting states of focussed attention during tasks that require higher-order cognitive processing. It is these oscillations that research has shown to be present during meditation (Lutz et al. 2004).

The results above suggest that meditation changes the brain in ways that foster cognitive functioning both during meditation and after. Although neuroscience techniques have not been employed in youth meditation samples, it is plausible to argue that the established links between school meditation programmes and cognitive functioning may be underpinned by brain changes that are fostered in these students. Therefore, we turn next to evidence from schools that meditation improves cognitive functioning in the area of attention, processing speed, abstract reasoning and executive function (e.g. planning, goal-directed activity).

Meditation and Cognitive Functioning in Schools To date, there have been seven studies ( $n=$ $1,210)$ that have investigated the effects of meditation programmes upon cognitive functioning including 33 effect sizes. Of these, $73 \%$ reported a statistically significant finding with Cohen's $d$ ranging from 0.05 to 1.12 . Most of the effects for the relationship with meditation and cognitive functioning were small (67\%), a quarter $(21 \%)$ had a medium effect size and $12 \%$ of the results showed strong effect sizes. The most commonly studied cognitive variable in school meditation research has been attention. Undoubtedly, attention is vital for student success, and it has been linked to academic performance (Lan et al. 2011), social competence (Fredricks et al. 2004) and well-being. Baijal et al. (2011)) examined the effects of a long-term daily Concentrative Meditation Programme in 13- to 15-year-old students of a public secondary school in India and sourced a control group of students from a nearby public school that had a similar socioeconomic and educational background but had not undertaken any meditation. In comparison to the non-meditating group, those students who attended the CMT school had higher scores on attentional alerting $(d=0.41)$, alerting accuracy $(d=0.34)$ and conflict monitoring accuracy $(d=0.39)$.

Similarly, Schonert-Reichl and Lawlor's (2010) evaluation of the ME intervention in fourth to seventh graders found that students exhibited strong, significant improvement in teacherrated attention and concentration between pre- and post-test for the students in the meditation group $(d$ effect size $=0.80)$ but not for those in the control group. Finally, the randomised controlled trial (RCT) study of Napoli et al. (described above) found statistically significant, moderate improvements in attention for the intervention group as measured by teachers pre- 
and post-test ratings using the attention deficit disorder with hyperactivity (ADD-H) Comprehensive Teacher Rating Scale $(d=0.35)$. The students in the meditation group also rated themselves to have significant, moderate improvements in selective attention $(d=0.42)$.

These empirical findings are supported by Campion and Rocco's (2009) qualitative evaluation of mindfulness, which also reported that students had gained greater attention and concentration skills. Forty-five per cent of students interviewed in this study reported that they now found it easier to concentrate on their schoolwork. One student commented, "You are more concentrated, but you are just not hyper and stuff; you are just more focusing."

School meditation studies have also considered other cognitive variables aside from attention. For instance, So and Orme-Johnson (2001) investigated the effects of TM on fluid intelligence, information processing speed, practical intelligence, field independence and creativity. Practical intelligence refers to non-intellectual abilities that predict physical health and well-being, including success at work and relationships. Field independence reflects psychological traits such as cognitive functioning, social behaviour and personality that predict academic success. Fluid intelligence is the ability to reason quickly and to think abstractly. When compared to the napping group and the no interest group, the intervention group demonstrated significant improvements for all variables except fluid intelligence (Cohen's $d$ ranged from 0.36 for information processing speed to 1.00 for creativity). Similar results were found by Warner (2005), who showed that the students in the TM group scored higher on working memory $(d=0.45)$, flexibility $(d=0.34)$, reflectivity $(d=1.12)$ and conservation tasks (e.g. detecting the conservation attributes of number, substance, weight and volume displacement) $(d=0.39)$, even after controlling for age, verbal intelligence and performance intelligence. Furthermore, within the meditation groups, practice length was correlated with improved working memory, reflectivity, performance on conservation tasks and verbal intelligence.

Flook et al. (2010) examined the effectiveness of Mindfulness Awareness Practices (MAPs) on executive functioning with second- and third-graders (mean age 8.23). Students assigned to the MAPs programme $(n=32)$ received sixteen 30-min sessions over an 8-week period, delivered by trained meditation instructors. The results showed no difference between groups for executive functions. However, greater improvements in metacognition, behavioural regulation, overall executive functions and the ability to shift, initiate and monitor attention were observed in students with poorer initial scores who underwent MAPs training compared to controls.

A number of trends were evident from the data. First, the effects of TM were more consistently positive and significant with 21 of the $25(84 \%)$ of the reported relationships significant in comparison with the mindfulness or mixed meditation programmes with 3 of the $10(30 \%)$ reported relationships being significant. However, the benefits of TM may derive from the fact that the TM sessions were also for a longer duration ( $>24$ weeks) and had higher session frequency ( $>$ once per day) than the other meditation interventions. Indeed, the programmes, which took more than 24 weeks, significantly impacted cognitive function variables $84 \%(n=25)$ of the time, while only $30 \%$ of the interventions that were between 6 and 24 weeks were significant. Similarly, session frequencies that were more than once per day were significant $85 \%$ of the time $(n=26)$, while sessions that were weekly were significant only $22 \%$ of the time $(n=9)$. The effects of meditation on cognition were more significant for high school students $(85 \% ; n=21)$ versus elementary school students $(38 \% ; n=13)$. Instructor type was also an important factor, and meditation practice run by teachers had $86 \%(n=22)$ of the results being significant in comparison to those run by other instructors $(22 \% ; n=9)$. Again, in this case, there was significant confounding across the variables, with the majority of studies which used TM, also had a long duration, high frequency, high school students, and a 
teacher facilitator. As a result, determining the unique effects of each programme characteristic is difficult.

\section{Meditation, Emotional Regulation and Student outcomes}

Emotional Regulation and Student Outcomes Emotion regulation is the capacity to appropriately monitor, evaluate and modify emotional reactions. Inability to regulate one's emotions has a negative impact upon well-being. Specifically, research has found that low emotional regulation is associated with higher levels of alexithymia, depression, neuroticism, somatic symptomatology and stress (Dawda and Hart 2000; Parker et al. 2001). In school students, McCraty et al. (1999) demonstrated significant improvements (e.g. better stress management and better anger management) in middle school pupils who were taught effective selfmanagement/emotional regulation techniques. Emotion regulation is also significantly related to social competence and research shows that emotional regulation is associated with one's capacity for empathy, ability to manage moods around others, peer-reported pro-social behaviours, and peer-reported anti-social behaviours (Ciarrochi et al. 2000; Mavroveli and SánchezRuiz 2011). In a longitudinal study, Eisenberg et al. (1995) assessed the relationship between emotionality, regulation and social function in 6-8 year olds and reported that individual differences in emotional regulation were associated with social-behavioural changes.

The relationship between emotional regulation and academic performance has been of great interest to researchers and educators, with correlational and longitudinal studies highlighting the positive associations between social emotional variables and academic performance (e.g. Caprara et al. 2000; Wang et al. 1997). Emotional regulation has also been shown to influence academic achievement. Emotional regulation is positively associated with academic success in kindergarten (Graziano et al. 2007), middle school (Gumora and Arsenio 2002) and university students (MacCann et al. 2011), even when controlling for IQ and cognition-related abilities. The analysis of Durlak et al. (2011) of 35 studies $(N=125,396)$ found a significant association between social-emotional learning, a key aspect of which is emotional regulation, and academic achievement. The capacity to self-regulate assists student to become disciplined with their learning habits, assists students to manage the stress of academic demands and persist in the face of academic challenges (Wang et al. 1997; Zins et al. 2004). Students with high levels of emotional regulation may also be less vulnerable to the effects of negative emotion and stress within examination contexts (MacCann et al. 2011).

Meditation and the Neurological Substrates of Enhanced Emotional Regulation The potential for meditation to be used as a tool to improve emotional regulation was one of the foundational questions asked in early meditation research and spawned the scientifically designed MBSR programme (Allen et al. 2006; Chiesa and Serretti 2009). Neuroscience suggests that one way in which meditation assists people in developing emotional regulation is through its effect on increased activity in the anterior cingulate cortex (ACC) (Cahn and Polich 2006; Lutz et al. 2008b; Zeidan et al. 2011). The ACC is thought to play a role in processing emotion, empathy and conflict (Grabenhorst et al. 2008; Lutz et al. 2008a). Increased activity in this region may account for the emotional regulation commonly reported as a product of meditation (Fredrickson et al. 2008; Goldin and Gross 2010). In addition to the link between meditation and increased activity in the ACC, research has shown a link between meditation and the thickness of the ACC. Grant et al. (2010) found increased cortical thickness in the ACC of 17 long-term meditators (minimum $1,000 \mathrm{~h}$ practice) compared to 17 controls. In similar findings from Hölzel et al. (2011), changes in grey matter density were tracked over an 8-week MBSR 
intervention with adults. Sixteen meditation naive participants spent an average of 27 min a day practicing mindfulness exercises. The researchers found increased grey matter density in the left hippocampus, an area strongly implicated in emotional regulation and also involved in learning and memory (Milad et al. 2007; Squire 1992). Increased grey matter density was also observed in the posterior cingulate cortex (PCC), temporo-parietal junction (TPJ) and cerebellum. The PCC and TPJ are areas involved in conscious self-referential experiences and conscious awareness of emotional states.

In another study linking meditation to structural changes in the hippocampus, Luders et al. (2009) observed significantly larger right hippocampal volume in 22 long-term meditators (minimum 5 years practice across a range of meditation styles) compared to 22 controls through the analysis of high-resolution magnetic resonance imaging (MRI) data. Hölzel et al. (2011) also utilised MRI analysis to observe increased grey matter density in the left hippocampus in 16 previously meditation-naive participants compared to 17 controls following an 8 -week MBSR intervention. The results of the studies outlined above suggest that plasticity in the hippocampus, ACC, PCC and TPJ may respond to mindfulness training. In the study of Hölzel et al. (2011), brain changes occurred after a relatively brief training period. Neuroscience has also found a relationship between meditation and the activity and size of the amygdala. The amygdala plays a central role in emotional processing and is specifically involved in responding to discursive emotions such as stress and fear (Hölzel et al. 2009). These findings may partly explain the mechanism behind improved emotional regulation and reduced stress reported as a function of meditation. For example, a functional magnetic resonance imaging (fMRI) study by Brefczynski-Lewis et al. (2007) reported reduced amygdala activity in long-term meditators (minimum 10,000 h practice) compared to controls in response to emotional sounds during a focussed attention meditation task. In addition, longterm meditators showed greater activity in the frontoparietal and temporal cortices, which assist in response inhibition. Hölzel et al. (2009) also observed reduced grey matter density in the right amygdala in 26 participants of an 8-week MBSR programme from pre- to post-test. Reductions in the amygdala coincided with reduced self-reported stress levels.

The neuroscience findings suggest that meditation creates plasticity in the regions of the brain that foster emotional regulation. As such, in line with our argument for cognitive functioning above, we suggest meditation at school might foster brain changes that enhance emotional regulation and this supports well-being, social competence and academic achievement.

Meditation and Emotional Regulation in Schools We located six studies $(n=762)$ that investigated the relationship between mediation and emotional regulation. Seventeen effects sizes were calculated with a combined sample size of 698 participants. Forty-one per cent of the results found that meditation had a significant effect on emotional regulation. Seventy-one per cent of the effects were small, $24 \%$ were medium and $6 \%$ were strong. Studies showed significant effects of meditation on various facets of emotional regulation such as awareness, control and clarity. Broderick and Metz (2009) reported improvements in emotional regulation in 120 adolescent students who took part in a mindfulness programme as part of their health curriculum. Students reported greater awareness of their emotions as they were experiencing them, with half of the participants reporting that the most important outcome of the programme was learning how to process stressful thoughts and emotions. In Schonert-Reichl and Lawlor's (2010) study, students who underwent the ME programme showed significant reductions in aggression $(d=0.52)$ and oppositional/disregulated behaviour $(d=0.43)$ compared to no change in the control group. Similarly, the fourth- and fifth-grade students of Mendelson et al. (2010) showed significant improvement in self-reported rumination $(d=0.70)$, intrusive thoughts $(d=$ 
$0.51)$ and emotional arousal $(d=0.64)$. Students in the study of Joyce et al. (2010) showed significant reductions in emotional/behavioural difficulties $(d=0.38)$ after the meditation intervention.

Qualitative research has also identified that emotional regulation is positively influenced through meditation. For example, in Rosaen and Benn's (2006) qualitative interviews with middle-school students, the students reported that they had cultivated better emotional control and were better able to handle stress. Similarly, in Campion and Rocco's (2009) qualitative study, $80 \%$ of the students stated that meditation had helped them to be calmer and more relaxed, and $36 \%$ reported that it had helped them manage their anger. One student commented: "You are a lot more relaxed afterwards, you get to clear your mind and it calms you down if you are a bit angry or stressed or something" (p. 51). In Campion and Rocco's (2009) study, $84 \%$ of the teachers reported that the students were calmer, and $37 \%$ reported that students had better control of their anger.

In summarising the effect sizes, type of meditation practice had some influence on the percentage of significant effects of meditation on emotion regulation, with mindfulness practice showing a high percentage $(66 \% ; n=12)$ in comparison to mixed designs $(0 \% ; n=$ $7)$. Interventions with lower durations $(<6$ weeks) had a lower percentage of significant findings $(10 \% ; n=10)$ compared to interventions that lasted between 6 and 24 weeks $(77 \% ; n=9)$. Daily meditation sessions had a higher percentage of significant findings $(55 \% ; n=9)$ compared with weekly practice $(12.5 \% ; n=8)$. A larger number of significant effects were found on emotion regulation for middle-school students $(71 \% ; n=7)$ compared to high school students $(10 \% ; n=10)$. Studies with teacher-led meditation reported a higher percentage of significant improvements $(66 \% ; n=6)$ on emotion regulation compared to meditation run by external instructors $(30 \% ; n=13)$.

\section{Methodological Considerations and Future Research}

The results of this review must be considered within a number of methodological considerations. For example, a major weakness in the field is the fact that many of the published studies had evaluated the meditation programme in the pilot stage and have only considered the immediate effects of the programme. Thus, although we can provide conclusions above about the short-term benefits, there can be no firm conclusions drawn about whether the benefits are sustained over time. The studies have predominantly come from schools in Western countries. There were no studies published from Europe nor the Middle East or Africa. Only two studies were published from schools in Eastern countries (Taiwan and India). Hence, it would be unwise to generalise from this review beyond a Western context.

The majority of the studies were unable to use random assignment due to specific year levels being used or particular student groups being targeted for the intervention. Thus, a primary factor limiting the interpretation in many of the studies was the lack of an equivalent control group.

The meditation programmes have commonly been evaluated using student subjective selfreport measures; thus, common-source bias is a concern. Seven studies also used teacher reports. However, the use of teacher ratings, while helping to overcome single source bias, may have also compromised the validity of results given that teachers were not blind as to which students were undertaking meditation (e.g. Joyce et al. 2010; Napoli et al. 2005).

To date, there has been no research studying the neurological impact of meditation in youth samples. In adult studies, technologies such as EEG and fMRI are being used to show that meditation is linked with changes in neurological structure (Hölzel et al. 2011), neuroelectrical 
activity (Lagopoulos et al. 2009), neurochemical activity (Kjaer et al. 2002) and hormonal changes (MacLean et al. 1997). However, none of these neurological changes have been directly tested in school children. This is puzzling given that the traditional remit of schools was to develop the brainpower of students. If researchers examining the effects of meditation were able to demonstrate brain-related changes in students using neurological assessments, this would prove a powerful argument for the widespread introduction of meditation in schools.

The need to overcome these methodological weaknesses in the field, combined with the trends/findings in this review paper, point towards some interesting areas for future research. One key area for future research relates to the most effective meditation practices to use in schools. Transcendental meditation programmes had a higher percentage of significant effects than mindfulness-based and other types of meditation programmes except in the outcome of emotional regulation where mindfulness had a bigger number of significant effects. However, TM was typically used with programmes that lasted for longer durations and were more likely to be practised daily, and these two variables were shown to positively impact upon the outcomes of meditation.

It is difficult to make judgements about which types of meditation are most effective with the current evidence available because there was no consistency used in the samples, designs and surveys. Systematic comparisons between the different types of meditative practices are very limited. One exception is So and Orme-Johnson (2001) who employed the use of contemplation meditation in addition to TM and a control group. Unlike TM, which improved performance on all cognitive measures and reduced anxiety relative to the control group, contemplation meditation only increased performance on inspection time and field independence and demonstrated a trend towards increased anxiety. Future research needs to follow the example of So and Orme-Johnson (2001) and compare the effectiveness of different meditation types using RCT designs, so that matched samples can be used and important elements of the study are equivalent such as programme duration, frequency of session and type of instructors. Moreover, the use of RCT designs can help researchers to determine if different types of meditation are suitable to different contexts, school types, age groups and student needs. It is unlikely that there is a "one size fits all" meditation for schools. Rather, it is more likely that different meditation practices will be more effective in different settings, in different student groups and across different age groups.

More fine-tuned research is needed to understand the optimal frequency with which students are best to practise meditation at school. The current review found greater results when meditation was practiced more than once per day. For example, with respect to wellbeing outcomes, $67 \%$ of the effects were significant for more than once daily practice compared to daily practice significant $(40 \%)$ and weekly practice $(50 \%)$. With respect to cognitive function, session frequencies that were more than once per day were significant $85 \%$ of the time, while sessions that were weekly were significant only $22 \%$ of the time. However, for schools to introduce a multiple-daily practice of meditation something else in the timetable must be forgone. Thus, the research needs to clearly show that frequent meditation will promote student outcomes to a greater degree than that activity which has been removed from the timetable.

Similarly, more research is needed to understand the optimal amount of time to spend meditating for each session. Unfortunately, the inconsistencies in reporting practice time in the studies reviewed has made it difficult to ascertain how much of an impact time spent meditating has on outcomes. A small number of studies did consider time spent meditating; for example, Warner (2005) discovered a correlation between the length of time in practice and performance on working memory, reflectivity, conservation and verbal intelligence tests. Huppert and Johnson (2010) also found a relationship between length of meditation time 
and well-being. In the research of Hölzel et al. (2011), adults who meditated for 27 min a day produced changes in their brain within 8 weeks. However, sessions of this length are unlikely to be feasible at schools. In addition, length of time for meditation may need to be shorter for younger students (Semple et al. 2005).

Future research needs to be conducted on programme duration and instructor type. These two elements may be related to each other as longer programmes are more likely to occur in schools if teachers guide the meditation rather than having to use an external instructor. In this review, programmes of longer duration had a higher number of significant effects, but with only five studies running programmes for over 6 months, further research is required. When meditation is delivered by a teacher, a higher percentage of significant results for social competence outcomes was found when the teacher was the facilitator $(75 \%)$ compared to other instructors $(20 \%)$. Research is needed to understand what it is about the relationship between student and teacher that fosters greater results for meditation programmes and then to use this knowledge to further enhance the efficacy of teacher-delivered mediation at school.

Another area that requires research is the need to develop meditation education that is age appropriate. Schonert-Reichl and Lawlor (2010) speculated that developmental changes between preadolescents and early adolescents might account for the different effects of meditation upon general self-concept after meditation. Baijal et al. (2011) also found age-related effects of meditation upon conflict monitoring. Warner's (2005) study was sensitive to developmental effects and used two different variants of TM with two different age groups: TM was used with students over the age of 10, while Words of Wisdom was used with students who were aged 10 or younger. This review found that high school students had a higher percentage of significant effects for well-being and cognitive function compared to middle and elementary school students. However, middle school students had a higher percentage of significant effects for emotional regulation compared to high school students. In order to achieve the greatest benefits from school meditation interventions, more consideration of the age-related needs of students is required.

The effects of meditation on academic achievement needs further exploration. Only three published studies have examined the relationship between meditation and academic achievement and insufficient evidence has yet to be accumulated. This is a critically important area in need of additional research given performance-based funding frameworks for educators in schools.

Finally, the use of new methods such as biotesting (e.g. salivary cortisol samples to assess whether meditation reduces stress in students) and neuroscience methods such as EEG and fMRI to track the potential effect of meditation on electrical activity, neural activity and changes in brain blood flow and brain structures are also needed to test the two propositions in this paper.

\section{Conclusions}

The current paper reviewed evidence as to the effects of meditation upon student well-being, social competence and academic achievement and offers some broad conclusions. First, school-based meditation is beneficial in the majority of cases and $61 \%$ of the results were significant. Second, the majority of effects of meditation upon student outcomes are small. This finding is not unexpected given the multitude of factors that contribute to student wellbeing, social competence and academic achievement. Small effects should not be dismissed, and some would argue that "every little bit helps" when it comes to fostering student success. It must also be noted that $33 \%$ of the effects sizes were medium or strong. Third, results from the current review indicate that meditation programmes can be made more efficacious by increasing programme duration, by encouraging twice daily (or more) meditation and by having the 
teacher deliver the programme. Transcendental meditation programmes had a higher percentage of significant effects than mindfulness-based and other types of meditation programmes, but this may be to do with the settings and programme delivery rather than the technique itself. Fourth, the review also suggests that meditation programmes will be more effective when they are designed in ways that deliberately increase cognitive functioning and emotional regulation.

The promise of contemplative education is attractive, and much could be gained if this promise is realised. While contemplative practice is age old, the scientific journey into meditation in schools is only just beginning. We hope this review paper offers a solid platform for future researchers to design high quality programmes for schools.

\section{Appendix 1}

Effects sizes for each study are presented in Table 3. The next sections outline each study in more detail. The experimental designs can be classified into three categories relevant to ES computations: (1) independent groups designs, in which between-groups comparisons were made at one time point, (2) repeated-measures (pre-post) and matched groups designs, and (3) independent groups pre-post designs, in which measures were administered to both groups before and after intervention. As detailed in Morris and DeShon (2002), calculation of $d$ differs in each of these designs, and they can only be compared if the SD used is the same or can be transformed into the same metric. The $d$ for independent groups $\left(\mathrm{d}_{\mathrm{IG}}\right)$ uses the post-test $\mathrm{SD}\left(\mathrm{SD}_{\text {post }}\right)$, and the repeated measures $d\left(\mathrm{~d}_{\mathrm{RM}}\right)$ uses the $\mathrm{SD}$ of the difference score $\left(\mathrm{SD}_{\mathrm{D}}\right)$. The calculation of $d$ for the independent groups pre-post design $\left(\mathrm{d}_{I G P P}\right)$ within the CMA software program may use either the post-test SD or the change score SD, to different result. We were limited by the data available; some authors provided pre- and post-test statistics, while others provided change statistics. As such, some $\mathrm{dI}_{\mathrm{GPP}}$ results were computed with $\mathrm{SD}_{\text {post }}$ and others with $\mathrm{SD}_{\mathrm{D}}$. The final column in Table 1 provides the details of the design and SD used for each ES calculation.

An additional complexity was that some authors provided covariance-adjusted means, in which post-test scores were adjusted for pre-test values. The difference between these adjusted means is unlikely to be comparable to the treatment effects in other designs (Morris \& DeShon 2002). Similarly, the provision of statistics by a number of authors that had been adjusted for one or more demographic covariates (e.g., IQ, age, gender, etc.) limits the comparability of treatment effects between the studies reviewed in this paper. Therefore, the significant variability in the experimental design and data used for computations amongst the studies reviewed precludes comparison between the effect sizes.

Open Access This article is distributed under the terms of the Creative Commons Attribution License which permits any use, distribution, and reproduction in any medium, provided the original author(s) and the source are credited.

\section{References}

Aftanas, L. I., \& Golocheikine, S. A. (2001). Human anterior and frontal midline theta and lower alpha reflect emotionally positive state and internalized attention: High-resolution EEG investigation of meditation. Neurosci Lett, 310, 57-60. doi:10.1016/j.bbr.2011.03.031.

Allen, N. B., Chambers, R., \& Knight, W. (2006). Mindfulness-based psychotherapies: A review of conceptual foundations, empirical evidence and practical considerations. Australian and New Zealand Journal of Psychiatry, 40, 285-294. doi:10.1080/j.1440-1614.2006.01784. 
Baijal, S., Jha, A. P., Kiyonaga, A., Singh, R., and Srinivasan, N. (2011). The influence of concentrative meditation training on the development of attention networks during early adolescence. Frontiers in Psychology, 2. doi: 10.2289/fpsy.2011.00153.

Beauchamp, M. H., \& Anderson, V. (2010). SOCIAL: An integrative framework for the development of social skills. Psychol Bull, 136(1), 39-64. doi:10.1037/a0017768.

Bernard, M., \& Walton, K. (2011). The effect of You Can Do It! Education in six schools on student perceptions of wellbeing, teaching, learning and relationships. Journal of Student Wellbeing, 5, 22-37.

Black, D. S., Milam, J., \& Sussman, S. (2009). Sitting-meditation interventions among youth: A review of treatment efficacy. Pediatrics, 124, 532-541. doi:10.1542/peds.2008-3434.

Bögels, S. M., Hoogstad, B., Dun, L., Schutter, S., \& Restifo, K. (2008). Mindfulness training for adolescents with externalising disorders and their parents. Behav Cogn Psychother, 36, 1-17. doi:10.1017/s1352465808004190.

Brefczynski-Lewis, J. A., Lutz, A., Schaefer, H. S., Levinson, D. B., \& Davidson, R. J. (2007). Neural correlates of attentional expertise in long-term meditation practitioners. Proc Natl Acad Sci, 104, 11483-11488. doi:10. 1073/pnas.0606552104.

Broderick, P., \& Metz, S. (2009). Learning to BREATHE: A pilot trial of a mindfulness curriculum for adolescents. Advances in School Mental Health Promotion, 2, 35-46. doi:10.1080/1754730x.2009.9715696.

Burt, K. B., Obradović, J., Long, J. D., \& Masten, A. S. (2008). The interplay of social competence and psychopathology over 20 years: Testing transactional and cascade models. Child Dev, 79(2), 359-374. doi: 10.1111/j.1467-8624.2007.01130.x.

Cahn, B. R., \& Polich, J. (2006). Meditation states and traits: EEG, ERP, and neuroimaging studies. Psychol Bull, 132, 180-211. doi:10.1037/0033-1909.132.2.180.

Campion, J., \& Rocco, S. (2009). Minding the mind: The effects and potential of a school-based meditation program for mental health promotion. Advances in School Mental Health Promotion, 2, 47-55. doi:10.1080/ 1754730x.2009.9715697.

Caprara, G. V., Barbaranelli, C., Pastorelli, C., Bandura, A., \& Zimbardo, P. G. (2000). Prosocial foundations of children's academic achievement. Psychol Sci, 11, 302-306. doi:10.1111/1467-9280.00260.

Chano, J. (2012). An education in awareness: Recovering the heart of learning through contemplation. International Journal of Asian Social Science, 2, 106-110.

Chiesa, A., \& Serretti, A. (2009). Mindfulness-based stress reduction for stress management in healthy people: A review and meta-analysis. J Altern Complement Med, 15, 593-600. doi:10.1089/acm.2008.0495.

Ciairano, S., Visu-Petra, L., \& Settanni, M. (2007). Executive inhibitory control and cooperative behavior during early school years: A follow-up study. J Abnorm Child Psychol, 35(3), 335-345. doi:10.1007/s10802-0069094-z.

Ciarrochi, J. V., Chan, A. Y., \& Caputi, P. (2000). A critical evaluation of the emotional intelligence construct. Personality and Individual Differences, 28, 539-561. doi:10.1016/S0191-8869(99)00119-1.

Clonan, S. M., Chafouleas, S. M., McDougal, J. L., and Riley-Tillman, T. C. (2004). Positive psychology goes to school: Are we there yet? Psychology in the Schools, 41, 101-110. doi: 10/ 1002.pits.10142.

Cohen, J. (1988). Statistical power analysis for the behavioural sciences (2nd ed.). Hillsdale, NJ: Erlbaum.

Compton, R. J. (2000). Ability to disengage attention predicts negative affect. Cognition \& Emotion, 14, 401415. doi:10.1080/026999300378897.

Conway, A. R., Cowan, N., Bunting, M. F., Therriault, D. J., \& Minkoff, S. R. (2002). A latent variable analysis of working memory capacity, short-term memory capacity, processing speed, and general fluid intelligence. Intelligence, 30, 163-183. doi:10.1016/S0160-2896(01)00096-4.

Davidson, R. J., \& Lutz, A. (2008). Buddha's brain: Neuroplasticity and meditation. IEEE Signal Processing Magazine, 25, 176-174.

Davidson, R. J., Kabat-Zinn, J., Schumacher, J., Rosenkranz, M., Muller, D., Santorelli, S. F., Urbanowski, F., Harrington, A., Bonus, K., \& Sheridan, J. F. (2003). Alterations in brain and immune function produced by mindfulness meditation. Psychosom Med, 65, 564-570. doi:10.1097/01.psy.0000077505.67574.e3.

Dawda, D., \& Hart, S. D. (2000). Assessing emotional intelligence: Reliability and validity of the Bar-On Emotional Quotient Inventory (EQ-i) in university students. Personality and Individual Differences, 28, 797-812. doi:10.1016/S0191-8869(99)00139-7.

Dietrich, A. (2003). Functional neuroanatomy of altered states of consciousness: The transient hypofrontality hypothesis. Conscious Cogn, 12, 231-256. doi:10.1016/s1053-8100(02)00046-6.

Durlak, J.A., Weissberg, R.P., Dymnicki, A.B., Taylor, R.D., \& Schellinger, K.B. (2011). The impact of enhancing students' social and emotional learning: a meta-analysis of school-based universal interventions. Child Development 82(1), 405-32.

Eisenberg, N., Fabes, R. A., Murphy, B., Maszk, P., Smith, M., \& Karbon, M. (1995). The role of emotionality and regulation in children's social functioning: A longitudinal study. Child Dev, 66, 1360-1384. doi:10.1111/ j.1467-8624.1995.tb00940.x. 
Flook, L., Smalley, S. L., Kitil, M. J., Galla, B. M., Kaiser-Greenland, S., Locke, J., \& Kasari, C. (2010). Effects of mindful awareness practices on executive functions in elementary school children. Journal of Applied School Psychology, 26, 70-95. doi:10.1080/15377900903379125.

Fredricks, J. A., Blumenfeld, P. C., \& Paris, A. H. (2004). School engagement: Potential of the concept, state of the evidence. Review of Educational Research, 74, 59-109. doi:10.3102/00346543074001059.

Fredrickson, B. L., Cohn, M. A., Coffey, K. A., Pek, J., \& Finkel, S. M. (2008). Open hearts build lives: Positive emotions, induced through loving-kindness meditation, build consequential personal resources. J Pers Soc Psychol, 95, 1045-1062. doi:10.1037/a001326.

Garrison Institute. (2005). Contemplation and education: A survey of programs using contemplative techniques in K-12 educational settings: A mapping report. Garrison, NY: Garrison Institute.

Goldin, P. R., \& Gross, J. J. (2010). Effects of mindfulness-based stress reduction (MBSR) on emotion regulation in social anxiety disorder. Emotion, 10, 83-91. doi:10.1037/a0018441.

Grabenhorst, F., Rolls, E. T., \& Parris, B. A. (2008). From affective value to decision making in the prefrontal cortex. European Journal of Neuroscience, 28, 1930-1939. doi:10.1111/j.1460-9568.2008.06489.x.

Grant, J. A., Courtemanche, J., Duerden, E. G., Duncan, G. H., \& Rainville, P. (2010). Cortical thickness and pain sensitivity in zen meditators. Emotion, 10, 43-53. doi:10.1037/a0018334.

Graziano, P. A., Reavis, R. D., Keane, S. P., \& Calkins, S. D. (2007). The role of emotion regulation in children's early academic success. $J$ Sch Psychol, 45, 3-19. doi:10.1016/j.jsp.2006.09.002.

Green, V. A., \& Rechis, R. (2006). Children's cooperative and competitive interactions in limited resource situations: A literature review. Journal of Applied Developmental Psychology, 27(1), 42-59. doi:10.1016/j. appdev.2005.12.002.

Greeson, J. M. (2009). Mindfulness research update: 2008. Complementary Health Practice Review, 14, 10-18. doi:10.1177/1533210108329862.

Grossenbacher, P. G., \& Parkin, S. S. (2006). Joining hearts and minds: A contemplative approach to holistic education in psychology. Journal of College and Character, 7, 1-13.

Gumora, G., \& Arsenio, W. F. (2002). Emotionality, emotion regulation, and school performance in middle school children. J Sch Psychol, 40, 395-413. doi:10.1016/S0022-4405(02)00108-5.

Hanif, A., Ferrey, A. E., Frischen, A., Pozzobon, K., Eastwood, J. D., Smilek, D., \& Fenske, M. J. (2012). Manipulations of attention enhance self-regulation. Acta Psychol (Amst), 139, 104-110. doi:10.1016/j. actpsy.2011.09.010.

Hölzel, B. K., Carmody, J., Evans, K. C., Hoge, E. A., Dusek, J. A., Morgan, L., \& Lazar, S. W. (2009). Stress reduction correlates with structural changes in the amygdala. Soc Cogn Affect Neurosci, 5, 11-17. doi:10. 1093/scan/nsp034.

Hölzel, B. K., Carmody, J., Vangel, M., Congleton, C., Yerramsetti, S. M., Gard, T., \& Lazar, S. W. (2011). Mindfulness practice leads to increases in regional brain gray matter density. Journal of Psychiatry Research, 191, 36-43. doi:10.1016/j.psycchresns.2010.08.006.

Huppert, F., \& Johnson, D. (2010). A controlled trial of mindfulness training in schools: The importance of practice for an impact on well-being. The Journal of Positive Psychology, 5, 264-274. doi:10.1080/ 17439761003794148.

Hunter, J. E., \& Schmidt, F. (2004). Methods of meta-analysis (2nd ed.). California: Sage Publications.

Jennings, P. A. (2008). Contemplative education and youth development. New Dir Youth Dev, 118, 101-105. doi: $10.1002 / y d .262$.

Joyce, A., Etty-Leal, J., Zazryn, T., Hamilton, A., \& Hassad, C. (2010). Exploring a mindfulness meditation program on the mental health of upper primary children: A pilot study. Advances in School Mental Health Promotion, 3, 17-25. doi:10.1080/1754730x.2010.9715677.

Kabat-Zinn, J. (1990). Full catastrophe living: Using the wisdom of your body and mind to face stress, pain and illness. New York: Delacorte.

Kabat-Zinn, J. (2003). Mindfulness-based interventions in context: Past, present, and future. Clinical Psychology: Science and Practice, 10, 144-156. doi:10.1093/clipsy.bpg016.

Kjaer, T. W., Bertelsen, C., Piccini, P., Brooks, D., Alving, J., \& Lou, H. C. (2002). Increased dopamine tone during meditation-induced change of consciousness. Cognitive Brain Research, 13, 255-259. doi: 10/1016/ s0926-6410(01)00106-9.

Lagopoulos, J., Xu, J., Rasmussen, I., Vik, A., Malhi, G. S., Eliassen, C. F., \& Ellingsen, Ø. (2009). Increased theta and alpha EEG activity during nondirective meditation. The Journal of Alternative and Complementary Medicine, 15, 1187-1192. doi:10.1089/acm.2009.0113.

Lan, X., Legare, C. H., Ponitz, C. C., Li, S., \& Morrison, F. J. (2011). Investigating the links between the subcomponents of executive function and academic achievement: A cross-cultural analysis of Chinese and American preschoolers. J Exp Child Psychol, 108, 677-692. doi:10.1016/j.jecp.2010.11.001.

Langdridge, D. (2004). Introduction to research methods and data analysis in psychology. Harlow: Pearson Education. 
Luders, E., Toga, A. W., Lepore, N., \& Gaser, C. (2009). The underlying anatomical correlates of long-term meditation: Larger hippocampal and frontal volumes of gray matter. Neuroimage, 45, 672-678. doi:10.1016/ j.neuroimage.2008.12.061.

Lutz, A., Greischar, L. L., Rawlings, N. B., Ricard, M., \& Davidson, R. J. (2004). Long-term meditators selfinduce high-amplitude gamma synchrony during mental practice. Proc Natl Acad Sci, 101, 16369-16373. doi:10.1073/pnas.0407401101.

Lutz, A., Brefczynski-Lewis, J., Johnstone, T., \& Davidson, R. J. (2008a). Regulation of the neural circuitry of emotion by compassion meditation: Effects of meditative expertise. PLOS ONE, 3, e1897. doi:10.1371/journal.pone.0001897.

Lutz, A., Slagter, H. A., Dunne, J. D., \& Davidson, R. J. (2008b). Attention regulation and monitoring in meditation. Trends in Cognitive Science, 12, 163-169. doi:10.1016/j.tics.2008.01.005.

MacCann, C., Fogarty, G. J., Zeidner, M., \& Roberts, R. D. (2011). Coping mediates the relationship between emotional intelligence (EI) and academic achievement. Contemporary Educational Psychology, 36, 60-70. doi:10.1016/j.cedpsych.2010.11.002.

MacLean, C. R., Walton, K. G., Wenneberg, S. R., Levitsky, D. K., Mandarino, J. P., Waziri, R., \& Schneider, R. H. (1997). Effects of the transcendental meditation program on adaptive mechanisms: Changes in hormone levels and responses to stress after 4 months of practice. Psychoneuroendocrinology, 22, 277-295. doi:10. 1016/s0306-4530(97)000003-6.

Mavroveli, S., \& Sánchez-Ruiz, M. J. (2011). Trait emotional intelligence influences on academic achievement and school behaviour. British Journal of Educational Psychology, 81, 112-134. doi:10.1348/2044-8279.002009.

McClelland, M. M., Acock, A. C., \& Morrison, F. J. (2006). The impact of kindergarten learning-related skills on academic trajectories at the end of elementary school. Early Childhood Research Quarterly, 21(4), 471-490. doi:10.1016/j.ecresq.2006.09.003.

McCraty, R., Atkinson, M., Tomasino, D., Goelitz, J., \& Mayrovitz, H. N. (1999). The impact of an emotional self-management skills course on psychosocial functioning and autonomic recovery to stress in middle school children. Integr Physiol Behav Sci, 34, 246-268. doi:10.1007/BF02688693.

Meiklejohn, J., Phillips, C., Freedman, M. L., Griffin, M. L., Biegel, G., Roach, A., and Saltzman, A. (2012). Integrating mindfulness training into K-12 education: Fostering the resilience of teachers and students. Mindfulness, 1-17. doi: 10.1007/s12671-012-0094-5.

Mendelson, T., Greenberg, M. T., Dariotis, J. K., Gould, L. F., Rhoades, B. L., \& Leaf, P. J. (2010). Feasibility and preliminary outcomes of a school-based mindfulness intervention for urban youth. Journal of Abnormal Child Psychology, 38, 985-994. doi: 10/1007/s10802-010-9419-x.

Milad, M. R., Wright, C. I., Orr, S. P., Pitman, R. K., Quirk, G. J., \& Rauch, S. L. (2007). Recall of fear extinction in humans activates the ventromedial prefrontal cortex and hippocampus in concert. Biol Psychiatry, 6I, 446-454. doi:10.1016/j.biopsych.2006.10.011.

Miles, M. B., and Huberman, A. M. (1994). Qualitative data analysis: An expanded sourcebook. Sage.

Morris, S. B., \& DeShon, R. P. (2002). Combining effect size estimates in meta-analysis with repeated measures and independent-groups designs. Psychol Methods, 7, 105-125. doi:10.1037/1082-989X.7.1.105.

Napoli, M., Krech, P. R., \& Holley, L. C. (2005). Mindfulness training for elementary school students: The attention academy. Journal of Applied School Psychology, 21, 99-125. doi:10.1300/J008v21n01 05.

Nidich, S. I., \& Nidich, R. J. (1989). Increased academic achievement at Maharishi School of the Age of Enlightenment: A replication study. Educ Comm Tech J, 109, 302-304.

Nidich, S., Mjasiri, S., Nidich, R., Rainforth, M., Grant, J., Valosek, L., Change, W., \& Zigler, R. (2011). Academic achievement and transcendental meditation: A study with at-risk urban middle school students. Educ Comm Tech J, 131, 556-564.

Oades-Sese, G. V., Esquivel, G. B., Kaliski, P. K., \& Maniatis, L. (2011). A longitudinal study of the social and academic competence of economically disadvantaged bilingual preschool children. Dev Psychol, 47(3), 747-764. doi:10.1037/t05579-000.

Parker, J. D., Taylor, G. J., \& Bagby, R. M. (2001). The relationship between emotional intelligence and alexithymia. Personality and Individual Differences, 30, 107-115. doi:10.1016/S0191-8869(00)00014-3.

Ramos, R., Freire, C., Julvez, J., Fernández, M. F., García-Esteban, R., Torrent, M., \& Olea, N. (2013). Association of ADHD symptoms and social competence with cognitive status in preschoolers. Eur Child Adolesc Psychiatry, 22(3), 1-12. doi:10.1007/s00787-012-0334-1.

Riggs, N. R., Greenberg, M. T., Kusché, C. A., \& Pentz, M. A. (2006). The mediational role of neurocognition in the behavioral outcomes of a social-emotional prevention program in elementary school students: Effects of the PATHS curriculum. Prev Sci, 7(1), 91-102. doi:10.1007/s11121-005-0022-1.

Robinson, M. D., Fetterman, A. K., Hopkins, K., \& Krishnakumar, S. (2013). Losing one's cool: Social competence as a novel inverse predictor of provocation-related aggression. Pers Soc Psychol Bull, 39(10), 1268-1279. doi: $10.1177 / 0146167213490642$.

Roeser, R. W., \& Peck, S. C. (2009). An education in awareness: Self, motivation, and self-regulated learning in contemplative perspective. Educational Psychologist, 44, 119-136. doi:10.1080/00461520902832376. 
Rosaen, C., \& Benn, R. (2006). The experience of transcendental meditation in middle school students: A qualitative report. Explore: The Journal of Science and Healing, 2, 422-425. doi:10.1016/j.explore.2006.06.001.

Rose-Krasnor, L. (1997). The nature of social competence: A theoretical review. Social Development, 6, 111135. doi:10.1111/1467-9507.00029.

Schonert-Reichl, K. A., \& Lawlor, M. S. (2010). The effects of a mindfulness-based education program on preand early adolescents' well-being and social and emotional competence. Mindfulness, 1, 137-151. doi:10. 1007/s12671-101-1100-8.

Seldon, A. (2011). Stillness in schools. Resurgence and Ecologist, 269. Retrieved from: http://www.resurgence. org/magazine/article3503.html

Seligman, M., \& Csikszentmihalyi, M. (2000). Positive psychology: An introduction. American Psychologist, 55, 5-14. doi:10.1037/0003-066X.55.1.5.

Seligman, M., Ernst, R., Gillham, J., Reivich, K., \& Linkin, M. (2009). Positive education: Positive psychology and classroom interventions. Oxford Review of Education, 35, 293-311. doi:10.1080/ 03054980902834563.

Semple, R. J., Reid, E. F., \& Miller, L. (2005). Treating anxiety with mindfulness: An open trial of mindfulness training for anxious children. Journal of Cognitive Psychotherapy, 19, 379-392. doi:10.1891/jcop.2005.19.4.379.

Siegle, G. J., Ghinassi, F., \& Thase, M. E. (2007). Neurobehavioral therapies in the 21st century: Summary of an emerging field and an extended example of cognitive control training for depression. Cognitive Therapy and Research, 31, 235-262. doi:10.1007/s10608-006-9118-6.

Singer, W. (1993). Synchronization of cortical activity and its putative role in information processing and learning. Annu Rev Physiol, 55(349), 374. doi:10.1234/12345678.

Singh, N. N., Lancioni, G. E., Joy, S. D. S., Winton, A. S., Sabaawi, M., Wahler, R. G., \& Singh, J. (2007). Adolescents with conduct disorder can be mindful of their aggressive behaviour. Journal of Emotional and Behavioural Disorders, 15, 56-63. doi:10.1177/10634266070150010601.

So, K. T., \& Orme-Johnson, D. W. (2001). Three randomized experiments on the longitudinal effects of the Transcendental Meditation technique on cognition. Intelligence, 29, 419-440. doi:10.1016/s0160-2896(01) 00060-8.

Squire, L. R. (1992). Memory and the hippocampus: A synthesis from findings with rats, monkeys, and humans. Psychol Rev, 99, 195-231. doi:10.1037/0033-295x.99.2.195.

Tallon-Baudry, C., \& Bertrand, O. (1999). Oscillatory gamma activity in humans and its role in object representation. Trends Cogn Sci, 3, 151-162. doi:10.1016/S1364-6613(99)01299-1.

Thompson, M., \& Gauntlett-Gilbert, J. (2008). Mindfulness with children and adolescents: Effective clinical application. Clin Child Psychol Psychiatry, 13, 395-407. doi:10.1177/1359104508090603.

Wadlinger, H. A., \& Isaacowitz, D. M. (2011). Fixing our focus: Training attention to regulate emotion. Pers Soc Psychol Rev, 15, 75-102. doi:10.1177/1088868310365565.

Wallace, A. (2006). The attention revolution: Unlocking the power of hte focused mind. Somerville, MA: Wisdom Publication.

Wall, R. B. (2005). Tai chi and mindfulness-based stress reduction in a Boston public middle school. J Pediatr Health Care, 19, 230-237. doi:10.1016/jpedhc.2005.02.006.

Wang, M. C., Haertel, G. D., \& Walberg, H. J. (1997). Learning influences. In H. J. Walberg \& G. D. Haertel (Eds.), Psychology and educational practice (pp. 199-211). Berkeley, CA: McCatchan.

Warner, T. Q. (2005). Awareness and cognition: The role of awareness training in child development. Journal of Social Behavior and Personality, 17, 47-64.

Waters, L. (2011). A review of school-based positive psychology interventions. The Australian Educational and Developmental Psychologist, 28, 75-90. doi:10.1375/aedp.28.2.75.

Waters, E., \& Sroufe, L. A. (1983). Social competence as a developmental construct. Developmental Review, 3(1), 79-97. doi:10.1016/0273-2297(83)90010-2.

Wickelgren, I. (2012). The education of character. Scientific American Mind, 23, 48-58. doi:10.1038/ scientificamericanmind0912-48.

Willig, C. (2008). Introducing qualitative research in psychology (2nd ed.). Maidenhead: Open University Press.

Zeidan, F., Martucci, K. T., Kraft, R. A., Gordon, N. S., McHaffie, J. G., \& Coghill, R. C. (2011). Brain mechanisms supporting the modulation of pain by mindfulness meditation. J Neurosci, 31, 5540-5548. doi: 10.1523/JNEUROSCI.5791-10.2011.

Zins, J. E., Weissberg, R. P., Wang, M. C., \& Walberg, H. J. (2004). Building academic success on social and emotional learning: What does the research say. New York, NY: Teachers College Press.

Zylowska, L., Ackerman, D. L., Yang, M. H., Futrell, J. L., Horton, N. L., Hale, T. S., Pataki, C., \& Smalley, S. L. (2008). Mindfulness meditation training in adults and adolescents with ADHD: A feasibility study. $J$ Atten Disord, 11, 737-746. doi:10.1177/1087054707308502. 